\title{
USO (Y ABUSO?) DEL DERECHO DE EXCEPCIÓN EN LOS ESTADOS MIEMBROS DE LA UNIÓN EUROPEA DURANTE LA PANDEMIA*
}

\author{
MARÍA DÍAZ CREGO \\ Letrada en el Servicio de Estudios del Parlamento Europeo \\ Profesora Titular de Derecho Constitucional de la Universidad de Alcalá
}

TRC, n. ${ }^{\circ} 48,2021$, pp. 399-431

ISSN 1139-5583

\begin{abstract}
SUMARIO
I. Introducción. II. El uso de estados de excepción constitucionales en los Estados miembros de la UE durante la pandemia: una primera aproximación III. Características de los estados de excepción declarados. IV. Control parlamentario sobre la declaración y prórroga de los estados de excepción. V. Control judicial de la declaración y prórroga de los estados de excepción. VI. A modo de conclusión.
\end{abstract}

\section{INTRODUCCIÓN}

La pandemia causada por el Covid-19, declarada por la Organización Mundial de la Salud el 11 de marzo de 2020, ha venido acompañada de una larga lista de medidas excepcionales dirigidas a tratar de evitar o, al menos, disminuir las

* El trabajo no expresa la opinión oficial del Parlamento Europeo, sino la personal de su autora. El trabajo se basa en la investigación realizada por un nutrido grupo de investigadores del Servicio de Estudios del Parlamento Europeo y ha sido parcialmente publicada en los siguientes estudios: Diaz Crego, M. y Kotanidis, S., States of emergency in response to the coronavirus crisis. Normative response and parliamentary oversight in the EU Member States during the first wave of the pandemic. EPRS, Parlamento Europeo, 2020 ; BINDER, K. y otros, States of emergency in response to the coronavirus crisis: Situation in certain Member States, EPRS, Parlamento Europeo, 2020; BENTZEN, N., y otros, States of emergency in response to the coronavirus crisis: Situation in certain Member States III, EPRS, Parlamento Europeo, 2020; AtANASsov, N., y otros, States of emergency in response to the coronavirus crisis: Situation in certain Member States II, EPRS, Parlamento Europeo, 2020; ALEXANDRE, Z., y otros, States of emergency in response to the coronavirus crisis: Situation in certain Member States IV, EPRS, Parlamento Europeo, 2020. Todos ellos disponibles en: https://www.europarl.europa.eu/thinktank/en/home.html 
tasas de propagación del virus, y a paliar las devastadoras consecuencias sociales y económicas de la pandemia. Esas medidas, especialmente las adoptadas por los Estados para tratar de frenar la pandemia, han compartido muchos elementos comunes: en todos los casos se trataba, con distinta intensidad, de frenar los contactos sociales a través de confinamientos, cierres fronterizos, cierres perimetrales de lugares con altas tasas de contaminación, teletrabajo, cierres de centros educativos, centros culturales y deportivos, etc. ${ }^{1}$. Los gobiernos han tenido un papel protagonista en la adopción de estas medidas, que han supuesto una limitación generalizada de derechos fundamentales que encuentra difícil parangón en otros momentos de nuestra historia reciente. En ese sentido, no es de extrañar que el análisis de los derechos fundamentales que se han visto afectados, así como de la necesidad y proporcionalidad de esas limitaciones haya sido y continúe siendo el objeto de largos e intensos debates jurídicos.

Sin embargo, desde el punto de vista constitucional, la gestión de la pandemia plantea otra cuestión igualmente relevante, véase en qué medida la forma y procedimiento utilizado para adoptar las medidas necesarias para atajar la pandemia han quebrado la tradicional separación de poderes de nuestros Estados constitucionales y los pesos y contrapesos que la acompañan en beneficio de un ejecutivo que haya actuado sin control ni freno alguno por parte del legislador, el poder judicial o las autoridades de niveles de gobierno sub-nacionales. Este interrogante habla de la salud de nuestros Estados constitucionales poniendo a prueba las bases mismas del constitucionalismo, entendido como un proyecto que promete la limitación del poder y la garantía de los derechos fundamentales de los ciudadanos. La cuestión que se plantea no es tanto si la gestión de la pandemia ha quedado en manos de ejecutivos «incontrolados», tal y como perfilaran las obras de Locke ${ }^{2}$ o Schmitt ${ }^{3}$, o por el contrario en manos de ejecutivos que han actuado bajo los frenos y contrapesos de los otros poderes del Estado en sintonía con el ideal Madisoniano. En las democracias consolidadas de nuestro entorno, esa dicotomía entre el paradigma del «soberano incontrolado» o del estado de excepción que se somete a las reglas del Estado de Derecho ${ }^{4}$, perfilándose como una institución legal dirigida a gestionar los tiempos excepcionales con miras a facilitar la vuelta a la normalidad, puede no tener extraordinaria trascendencia, en la medida en que el segundo modelo parece más que asentado, salvo en raras, aunque notables, excepciones. Sin embargo, la diferencia esencial puede quizás hallarse entre

1 Para el análisis del contenido de las medidas adoptadas por los Estados miembros durante la pandemia se recomienda el Oxford COVID-19 Government Response Tracker, Blavatnik School of Government (Disponible en: https://covidtracker.bsg.ox.ac.uk/stringency-map), que proporciona información desde el comienzo de la pandemia (enero 2020) hasta la fecha.

2 Locke, J., Segundo tratado sobre el gobierno civil (publicado por primera vez en inglés en 1689).

3 Schmitт, C., Dictatorship (publicado por primera vez en alemán en 1922).

4 Dyzenhaus, D., «Schmitt v Dicey: Are States of Emergency Inside or Outside the Legal Order?», Cardozo Law Review n. ${ }^{\circ}$ 27, 2006; Ginsburg, T. y Versteeg, M., «The Bound Executive: Emergency Powers During The Pandemic», Virginia Public Law and Legal Theory Research Paper, n. ${ }^{\circ}$ 52, 2020. 
modelos constitucionales que prevean mecanismos de control de las acciones del ejecutivo en tiempos de excepción puramente formales o modelos que prevean mecanismos de control sustantivos, tal y como apunta Dyzenhaus ${ }^{5}$.

En este contexto, el trabajo que se presenta analizará el marco jurídico utilizado por los Estados miembros de la Unión Europea para responder a la primera y las sucesivas olas de la pandemia (marzo 2020-junio de 2021) y la medida en que esa respuesta normativa pueda haber degenerado en un abuso de poder por parte del ejecutivo, en un ejercicio de poder sin controles efectivos. Aunque se ahondará en ello en la sección II del trabajo, el estudio centra su interés esencialmente en aquellos Estados miembros de la Unión que han declarado, en algún momento de la pandemia, un estado de excepción previsto en su texto constitucional y no tanto, en aquellos — la mayoría — que han respondido a la pandemia utilizando herramientas puramente legislativas. El análisis de este segundo grupo sería también de notable interés, en tanto la utilización de herramientas puramente legislativas para afrontar situaciones de crisis plantea interesantes cuestiones jurídicas, como por ejemplo, la eventual normalización de la excepción y la utilización de mecanismos de control que, por ser los ordinarios, pueden resultar inadecuados para gestionar una emergencia ${ }^{6}$. Pero, por razones de tiempo y de espacio, el análisis realizado se centra tan sólo en aquellos Estados miembros de la UE que han hecho uso de su Derecho de excepción para afrontar la pandemia y el objetivo no será otro que tratar de alcanzar alguna conclusión — aunque sea inicial - sobre cómo han funcionado los controles parlamentarios y judiciales durante la misma.

\section{EL USO DE ESTADOS DE EXCEPCIÓN CONSTITUCIONALES EN LOS ESTADOS MIEMBROS DE LA UE DURANTE LA PANDEMIA: UNA PRIMERA APROXIMACIÓN}

Los estudios de Derecho comparado realizados hasta la fecha sobre la gestión de la pandemia en el mundo tienden a indicar que la mayoría de los Estados han adoptado las medidas que han estimado necesarias para contener el virus haciendo uso de herramientas puramente legislativas, véase legislación específicamente adoptada con miras a hacer frente a la pandemia por Covid- 19 o legislación preexistente en materia de salud pública o de protección civil, que en ocasiones ha sido modificada para adaptarla a las exigencias de la actual pandemia. Tras la primera ola de la pandemia, Ginsburg y Versteeg daban cuenta

5 Dyzenhaus, D., The Constitution of Law: Legality in a Time of Emergency. Cambridge University Press, Cambridge, 2006.

6 Sobre el modelo legislativo de control de emergencias ver: Ferejohn, J. y Pasquino, P., «The law of the exception: A typology of emergency powers», International Journal of Constitutional Law, vol. 2, n. ${ }^{\circ} 2$, 2004, pp. 210-239. 
de los resultados de una investigación desarrollada en 106 Estados y señalaban que el $52 \%$ de esos Estados habían utilizado un modelo legislativo para hacer frente a la pandemia ${ }^{7}$.

Los Estados miembros de la Unión Europea no han sido una excepción. De los 27 Estados miembros, tan solo 10 declararon un Estado de excepción constitucional durante la primera ola de la pandemia (Bulgaria, República Checa, Estonia, Finlandia, Hungría, Luxemburgo, Portugal, Romania, Eslovaquia, España), cifra que se vio reducida a 5 Estados miembros durante la segunda (y la tercera y cuarta, en algunos casos) ola (Eslovaquia, República Checa, España, Hungría y Portugal). En el resto de los Estados, la respuesta normativa a la pandemia ha tenido su base en la ley y se ha producido haciendo uso de las herramientas que preveían bien instrumentos legislativos ordinarios bien normas con rango de ley, semejantes a nuestros Decretos-Leyes, en tanto eran adoptadas por el ejecutivo y objeto de algún tipo de control por parte del legislador . $^{8}$

Por supuesto, el marco normativo utilizado resulta mucho más complejo cuando se analiza con detalle en la medida en que muchos Estados miembros de la UE han hecho uso, en realidad, de varios instrumentos legales y constitucionales como base jurídica para la adopción de las medidas que se creían necesarias para atajar la pandemia en sus distintos estadios en una suerte de movimiento de escalada y desescalada en función de la evolución de los contagios ${ }^{9}$. Esa variedad se observa quizás con mayor claridad en el caso de los Estados miembros que han declarado un estado de excepción constitucional, en tanto parecen poder distinguirse varios momentos desde que la pandemia fuera declarada en marzo de 2020 hasta la fecha en que finaliza este trabajo (junio 2021): 1) en los primeros momentos tras la declaración de la pandemia y la llegada — más o menosvirulenta del virus a Europa, un grupo numeroso de Estados miembros declararon un estado de excepción previsto en el texto constitucional, en la mayoría de los casos por un periodo que no excedería los dos o tres meses; 2) entre los meses de mayo y junio de 2020, esos primeros estados de excepción expiraron y, aunque se mantuvieron distintas medidas de contención del virus, la base jurídica utilizada para su adopción pasó a ser únicamente la ley, en algunos casos, con la correspondiente declaración de una suerte de estado de emergencia legislativo; 3) con el aumento de los contagios durante el otoño de 2020, una parte de los Estados miembros que originalmente declaró un estado de excepción constitucional (Eslovaquia, República Checa, España, Hungría y Portugal), volvió a hacer uso de ese instrumento normativo, en ocasiones porque era el único que permitía la adopción de severas medidas de contención de la pandemia. Veamos esta línea temporal con más detalle.

7 Ginsburg, T. y Versteeg, M., op.cit.

8 Diaz Crego, M. y Kotanidis, S., op.cit.

9 Ibidem. 


\section{El recurso a los estados de excepción durante la primera ola de la pandemia (marzo-junio 2020)}

A la par que el Covid-19 se expandía haciendo caso omiso de las fronteras europeas, los Estados miembros de la UE adoptaron duras medidas de contención del virus bajo el amparo de distintos marcos normativos ${ }^{10}$. Como ya se indicó, 10 de los Estados miembros declararon estados de emergencia constitucionales: Hungría fue la primera en hacerlo, declarando el estado de riesgo extremo el 11 de marzo de 2020, y tras ella lo hicieron la República Checa y Estonia, el 12 de marzo; Bulgaria, el 13 de marzo; España, el 14 de marzo; Finlandia, Rumanía y Eslovaquia, el 16 de marzo; Luxemburgo, el 18 de marzo; y Portugal, el 19 de marzo.

Las razones que llevaron a los Estados miembros indicados a declarar un estado de excepción, mientras el resto de sus socios europeos decidían hacer frente a la pandemia con instrumentos puramente legislativos, son múltiples: en algunos casos, las razones fueron estrictamente jurídicas, mientras que en otros tenían más que ver con la gravedad de la situación en el país, con razones históricas o con la oportunidad política de declarar un estado de excepción.

En algunos Estados miembros de la UE, se optó por la utilización de instrumentos legislativos simplemente porque sus textos constitucionales forman parte del reducido grupúsculo de Constituciones que no recoge ningún estado de excepción ${ }^{11}$. En esta situación se encontraban Austria, Bélgica y Dinamarca, cuyos textos constitucionales no recogen ningún estado de excepción como tal, aunque sí prevén la posibilidad de que se transfieran competencias legislativas en situaciones de emergencia bien al Presidente de la Federación (Austria ${ }^{12}$ ), bien al monarca —véase, el ejecutivo (Dinamarca ${ }^{13}$ y Bélgica). Bélgica fue el único de estos tres Estados que hizo uso de la posibilidad de atribuir «poderes especiales» al ejecutivo ex artículo 105 de su texto constitucional durante la primera ola de la pandemia ${ }^{14}$, pero la mayoría de las medidas de contención se adoptaron, tanto en la primera ola como en las olas subsiguientes de la pandemia, sobre la base de las leyes de protección civil, de seguridad civil y de policía, lo que ha suscitado numerosas críticas ${ }^{15}$ y provocado un contencioso — todavía irresuelto— sobre la legalidad de las medidas ${ }^{16}$. Recientemente, el

10 Oxford COVID-19 Government Response Tracker, Blavatnik School of Government; Disponible en: https://covidtracker.bsg.ox.ac.uk/stringency-map. Ver los resultados desde marzo de 2020.

11 Diaz Crego, M. y Kotanidis, S., op. cit., p. 17.

12 Artículo 18 de la Constitución austriaca.

13 Ver Sección 23 del texto constitucional danés.

14 Los poderes especiales fueron atribuidos a través de dos leyes: Loi habilitant le Roi à prendre des mesures de lutte contre la propagation du coronavirus COVID-19 (I) (1) y Loi habilitant le Roi à prendre des mesures de lutte contre la propagation du coronavirus COVID-19 (II) (1), ambas de 27.03.2020.

15 Sobre la base legal utilizada y sus insuficiencias, ver: Bouhon, F. Jousten, A., Miny, X., y SLAUTSKY, E., «L'État belge face à la pandémie de Covid-19: esquisse d'un régime d'exception». Courrier hebdomadaire du CRISP 2020/1, n 2446, pp. 5-56.

16 Tras una decisión adoptada por el Tribunal de Primera Instancia de Bruselas (31.03.2021) señalando la falta de base jurídica adecuada de las medidas de contención adoptadas por el gobierno belga, la Corte 
ejecutivo belga ha presentado un proyecto de ley en el Parlamento con miras a proveer de una base legal menos incierta a las medidas de contención de la pandemia ${ }^{17}$.

En otros Estados miembros, la opción de no declarar un estado de excepción se debió a que, aunque las correspondientes constituciones sí preveían algún tipo de estado de excepción, éste no resultaba adecuado para hacer frente a la crisis sanitaria generada por el Covid-19. Tal era el caso en Francia, Chipre, Italia, Irlanda, Letonia, Grecia o Suecia, en los que los estados excepcionales se ciñen esencialmente a situaciones de guerra (Grecia, Italia, Chipre) o a conflictos armados o rebeliones o insurrecciones internas (Suecia, Letonia, Irlanda). Una mención especial merece quizás nuestra vecina Francia, en la medida en que, aunque ninguno de los dos regímenes de excepción previstos en su texto constitucional se entendía adecuado para atajar la pandemia - véase, el estado de sitio recogido en el art. 36 de la Constitución o los poderes excepcionales atribuidos al Presidente de la República ex art. $16^{18}$-, algunos autores han señalado que sí habría sido de aplicación el régimen legal previsto en la ley 55-385, de 3 de abril de 1955, que permite la declaración del estado de urgencia ante eventos que, por su naturaleza o gravedad, puedan considerarse una calamidad pública, entre otros supuestos. Sin embargo, las negativas connotaciones de este estado de emergencia, que ha sido declarado en varias ocasiones, entre otras, para hacer frente a los ataques terroristas que tuvieron lugar en París en $2015^{19}$, podrían estar en el origen de la creación de un nuevo régimen legal de carácter excepcional llamado a hacer frente a emergencias sanitarias y que ha sido utilizado para hacer frente a la pandemia desde los primeros embates de la misma ${ }^{20}$.

En otros Estados miembros, la cuestión no resultaba tan clara, en la medida en que alguno de los estados de excepción previstos en el texto constitucional permitía

de apelación de Bruselas decidió, el 7.06.2021, que esas medidas no eran manifiestamente ilegales ( . $^{\circ}$ asunto 2021/KR/17), pero cuestionó la constitucionalidad de las leyes que les sirvieron de base, reenviando la cuestión al Tribunal Constitucional.

17 El proyecto de ley fue presentado el 27.04.2021 y todavía sigue en discusión en la Cámara de Representantes belga (Projet de loi relatif aux mesures de police administrative lors d'une situation d'urgence épidémique, 27/04/2021 —el estado de tramitación puede seguirse en este link: https://www.lachambre.be/kvvcr/showpage. $\mathrm{cfm}$ ? section $=$ flwb\&language $=\mathrm{fr} \& \mathrm{cfm}=/ \mathrm{site} / \mathrm{wwwcfm} / \mathrm{flwb} / \mathrm{flwbn} . \mathrm{cfm}$ ? dossierID $=1951$ \&legislat $=55 \&$ inst $=\mathrm{K})$

18 Sobre la inadecuación de estas previsiones constitucionales a una crisis como la provocada por la pandemia, ver: BEAUD, O: «La surprenante invocation de l'article 16 dans le débat sur le report du second tour ses élections municipales». Jus Politicum, blog de la Revue internationale de Droit Constitutionnel, 23.03.2020 Disponible en: https://blog.juspoliticum.com/2020/03/23/la-surprenante-invocation-de-larticle -16-dans-le-debat-sur-le-report-du-second-tour-des-elections-municipales-par-olivier-beaud/)

19 Sobre la utilización de este régimen legal hasta la fecha, ver: Golia, A. JR.; Hering, L.; Moser, C.; Sparks, T., «Constitutions and Contagion. European Constitutional Systems and The Covid-19 Pandemic». MPIL Research Paper Series, n. ${ }^{\circ}$ 2020-42, pp. 16-17.

20 El nuevo estado de excepción sanitaria se creó a través de la Ley n. ${ }^{\circ}$ 2020-290, de 23.03.2020 (Loi n. ${ }^{\circ}$ 2020-290 du 23 mars 2020 d'urgence pour faire face à l'épidémie de covid-19 (1)), que modificó el Código de la Salud Publica. Sobre la posibilidad de aplicar el estado de urgencia previsto en la ley 55-385, ver: MIGNON, E.: 'L'état d'urgence sanitaire, quand, pourquoi, comment?'. AD Article, 20.03.2020 Disponible en: https://www.august-debouzy.com/fr/blog/1438-letat-durgence-sanitaire-quand-pourquoi-comment; BEAUD, O. y Guérin Bargues. C., "L'état d'urgence sanitaire : était-il judicieux de créer un nouveau régime d'exception? », Recueil Dalloz, n. ${ }^{\circ} 16,2020$, pp. 891-898. 
su declaración en situaciones de riesgo para el orden democrático, el sistema constitucional o la paz o el orden social y se planteó la cuestión de en qué medida la pandemia podía encajar en supuestos de contornos tan imprecisos. Así, por ejemplo, en Lituania, se cuestionó si el estado de emergencia previsto en el art. 84 (17) de la Constitución para hacer frente a situaciones de riesgo para el orden constitucional o la paz social podía o, incluso, debía haber sido declarado en lugar de utilizar la legislación en materia de enfermedades contagiosas y de protección civil, en tanto éstas no parecían ser base jurídica suficiente para la adopción de ciertas medidas de contención y tuvieron que ser modificadas a posteriori por el Parlamento ${ }^{21}$. En una línea semejante, la doctrina alemana ha discutido extensamente si podría declararse alguno de los estados de emergencia previstos en el texto constitucional como consecuencia de la pandemia: aunque la pandemia no parecía encajar en los supuestos considerados como emergencias externas, véase una agresión armada o un riesgo inminente de agresión (art. 91 de la Ley Fundamental) ${ }^{22}$, algunos autores subrayaron que podría quizás encajar en la noción de «desastre natural» que permite aplicar el art. 35 de la Ley Fundamental o podría considerarse una amenaza inminente para el orden democrático o la existencia de la Federación, tal y como exige el art. 91 del texto constitucional para la declaración de una emergencia interna, aunque tan solo si la situación en el país alcanzara ciertos niveles de gravedad ${ }^{23}$. Dado que este no parecía ser el caso, Alemania optó por hacer uso de su legislación en materia de enfermedades contagiosas desde la primera ola de la pandemia, aunque la norma utilizada como base jurídica ha sido modificada ya en varias ocasiones ${ }^{24}$. Debates semejantes también surgieron en $\mathrm{Malta}^{25}$ o en Eslovenia ${ }^{26}$.

Finalmente, en un escaso número de Estados miembros (Croacia, Países Bajos y Polonia), parecía posible la declaración de alguno de los regímenes de excepción previstos en el texto constitucional, pero no se consideró adecuado o necesario el

21 La batería inicial de medidas de contención se recogía en la Decisión del Gobierno lituano n. ${ }^{\circ} 207$, de 14.03.2020, que se fundaba en la Ley de Protección Civil y la Ley de Prevención y Control de Enfermedades Contagiosas en Humanos. Esta última sufriría una modificación notable en 31.03.2020, a través de la Ley n. ${ }^{\circ}$ XIII-2831. Sobre esta modificación y el debate interno, ver: Dagilyté, E., PAdskočimaité, A. y VainoRIENE, A.: Lithuania's Response to COVID-19: Quarantine Through the Prism of Human Rights and the Rule of Law, VerfBlog, 2020/5/14, https://verfassungsblog.de/lithuanias-response-to-covid-19-quarantine-through-the-prismof-human-rights-and-the-rule-of-law

22 Golia, A. JR.; Hering, L.; Moser, C.; Sparks, T.: op. cit., pp. 15-16.

23 Jürgensen, S. y Orlowski, F., Critique and Crisis: The German Struggle with Pandemic Control Measures and the State of Emergency, VerfBlog, 2020/4/19, https://verfassungsblog.de/critique-and-crisis-thegerman-struggle-with-pandemic-control-measures-and-the-state-of-emergency/

24 Ver la Ley para la prevención y el control de las enfermedades infecciosas en humanos (Infektionsschutzgesetz de 20.07.2000, BGBl. I S. 1045), modificada por última vez el 28.05.2021 (BGBl. I p. 1174). Sobre las modificaciones introducidas en la norma, ver: MANGOLD, A. K., Germany and COVID-19: A Most Eventful Year, VerfBlog, 2021/4/07, https://verfassungsblog.de/germany-and-covid-19-a-most-eventful-year/

25 De Gaetano, V. A., Covid-19 — the Maltese Response: Slow at First but Steady and Effective, VerfBlog, 2020/5/04, https://verfassungsblog.de/covid-19-the-maltese-response-slow-at-first-but-steady-and-effective/

26 Ver el capitulo sobre Eslovenia, Coronavirus pandemic in the EU - Fundamental Rights Implications, European Union Agency for Fundamental Rights, 4 May 2020. 
uso de tal recurso, lo que provocó intensas discusiones internas sobre la constitucionalidad de determinadas medidas restrictivas de derechos en alguno de esos Estados. En Polonia, por ejemplo, uno de los estados de excepción previstos en su texto constitucional —al menos ${ }^{27}$ — parecía encajar a la perfección con la situación provocada por la pandemia, al poder ser declarado en caso de desastres naturales (arts. 232 y 233 de la Constitución polaca), entre los que se incluye la propagación masiva de enfermedades infecciosas entre humanos, tal y como recoge el art. 3 de la Ley por la que se regula el estado de desastre natural ${ }^{28}$. A pesar de ello, las autoridades nacionales entendieron que las medidas de contención del virus podían adoptarse sobre la base de lo previsto en la Ley de enfermedades contagiosas, lo que adicionalmente permitía esquivar el control parlamentario que exigía la declaración de un estado de excepción, así como la celebración de las elecciones presidenciales que originalmente estaban previstas para el 10 de mayo de 2020 (segunda vuelta el 24 de mayo) y fueron finalmente pospuestas hasta el 28 de junio ${ }^{29}$. La opción fue criticada por varios autores, que consideraban insuficiente la base jurídica empleada por el ejecutivo para adoptar las medidas de contención del virus ${ }^{30}$, y censuraban la reiteración de la opción en el otoño de 2020, durante la segunda ola de la pandemia ${ }^{31}$.

Al igual que en Polonia, en Croacia, el debate sobre la declaración del estado de emergencia por desastres naturales previsto en el art. 17 del texto constitucional fue recurrente durante la primera ola de la pandemia ${ }^{32}$, aunque el ejecutivo decidió hacer uso de la legislación en materia de protección civil y de prevención de las enfermedades infecciosas para adoptar las medidas de contención necesarias, lo que requirió varias reformas de las normas indicadas ${ }^{33}$. La negativa a declarar el estado de emergencia tenía relevantes consecuencias prácticas en la medida

27 Se ha señalado que, además del estado de desastre natural, también el estado de emergencia constitucional podía haber sido declarado (art. 230 de la Constitucion polaca). En este sentido: SADURSKI, W., The Polish Presidential Campaign in the Shadow of the Pandemic, VerfBlog, 2020/3/18, https://verfassungsblog.de/ the-polish-presidential-campaign-in-the-shadow-of-the-pandemic/

28 Ustawa z dnia 18 kwietnia 2002 r. o stanie klęski żywiołowej. Disponible en: http://isap.sejm.gov. pl/isap.nsf/DocDetails.xsp?id= WDU20020620558)

29 El art. 228 (7) de la Constitución polaca impide la celebración de elecciones durante un estado de emergencia constitucional y hasta que no hayan transcurrido 90 días desde su finalización.

30 Jaraczewski, J., An Emergency By Any Other Name? Measures Against the COVID-19 Pandemic in Poland, VerfBlog, 2020/4/24, https://verfassungsblog.de/an-emergency-by-any-other-name-measures-againstthe-covid-19-pandemic-in-poland/; MatcZaK, M., Plague President, VerfBlog, 2020/5/05, https://verfassungsblog.de/plague-president/

31 Jaraczewski, J., The New Normal? - Emergency Measures in Response to the Second COVID-19 Wave in Poland, VerfBlog, 2021/3/24, https://verfassungsblog.de/the-new-normal-emergency-measures-in-responseto-the-second-covid-19-wave-in-poland/

32 Selanec, N., Croatia's Response to COVID-19: On Legal Form and Constitutional Safeguards in Times of Pandemic, VerfBlog, 2020/5/09, https://verfassungsblog.de/croatias-response-to-covid-19-on-legal-form-andconstitutional-safeguards-in-times-of-pandemic/

33 European Parliamentary Research Service, European Parliament, States of emergency in response to the coronavirus crisis: Situation in certain Member States III, June 2020, pp. 2-3. 
en que su declaración habría requerido la adopción de toda medida restrictiva de derechos a través de una mayoría de 2/3 en el Parlamento nacional frente a la mayoría ordinaria exigida para la limitación de derechos en condiciones de normalidad, reforzando así la posición del Parlamento en tiempos de crisis. A pesar de ello, el Tribunal Constitucional croata validó la opción elegida, subrayando que es la institución parlamentaria la que debe decidir si procede o no exigir la mayoría cualificada prevista en el art. 17 de la Constitución ${ }^{34}$, posición que ha sido criticada por la doctrina por ser excesivamente deferente y dejar en manos de una simple mayoría parlamentaria decisiones respecto de las cuales la Constitución buscaba un amplio consenso ${ }^{35}$.

El balance de la gestión de la primera ola de la pandemia en los Estados miembros de la UE parecía así claro: la mayoría de los Estados cuyos textos constitucionales contenían un estado de excepción constitucional adaptado a una situación de pandemia decidieron declararlo, y, tal y como se analizará con más detalle en los apartados III-V de este trabajo, esos estados de excepción presentaron ciertas características comunes: en general, se optó por el estado de excepción menos invasivo de los previstos en la constitución nacional; el carácter temporal de la emergencia quedaba asegurado, en muchos de los casos, por el propio texto constitucional; la mayoría de los parlamentos nacionales controlaron la declaración, así como las sucesivas prórrogas del estado de excepción declarado; y, en algunos casos, esa declaración fue sometida a control judicial.

2. La expiración de los estados de excepción constitucionales y el abanico de soluciones nacionales para ordenar la desescalada durante el verano de 2020 (junio-septiembre 2020)

La mayoría de los estados de excepción constitucionales declarados durante la primera ola de la pandemia en Europa expiraron entre mayo y junio de 2020. Portugal fue el primer Estado miembro en levantar el estado de emergencia constitucional, haciéndolo el 2 de mayo de 2020, y sus pasos fueron seguidos por Bulgaria (13 de mayo), Rumanía (14 de mayo), República Checa y Estonia (17 de mayo), Eslovaquia (13 de junio), Finlandia (15 de junio), Hungría (18 de junio), y España (20 de junio), hasta la expiración del estado de crisis declarado por Luxemburgo el día 24 de junio de 2020.

La expiración o el levantamiento de esos estados de excepción fue seguido de la aplicación de medidas de contención del virus más flexibles, enmarcadas en una estrategia de desescalada y caracterizadas, desde el punto de vista jurídico, por

34 Tribunal Constitutional croata, decision de 14.09.2020, n. ${ }^{\circ}$ U-I-1372/2020.

35 SELAneC, N., COVID-19 and the Rule of Law in Croatia: Majoritarian or Constitutional Democracy?, VerfBlog, 2021/4/27, https://verfassungsblog.de/covid-19-and-the-rule-of-law-in-croatia-majoritarian-orconstitutional-democracy/ 
estar fundadas bien en la legislación preexistente en materia de salud pública o protección civil — que en ocasiones fue modificada a fin de adaptarla a las necesidades de la pandemia-, o en legislación específica adoptada para hacer frente a la actual pandemia. En la República Checa, la gestión de la pandemia durante el verano de 2020 se realizó sobre la base de la preexistente Ley de Protección de la Salud Publica, que ha sido modificaba en reiteradas ocasiones desde marzo pasado ${ }^{36}$. También mantuvieron medias de contención del virus más laxas durante el verano de 2020 sobre la base de legislación preexistente, aunque modificada para adaptarla a las necesidades de la pandemia, Estonia ${ }^{37}$, Finlandia ${ }^{38}$ y España ${ }^{39}$, aunque es de señalar que algunas de las modificaciones legislativas que se introdujeron en estos países fueron temporales ${ }^{40}$. En Luxemburgo, la solución adoptada fue parcialmente diferente, en tanto el mantenimiento de ciertas medidas de contención del virus tras la expiración del estado de crisis se fundó en legislación ad hoc aprobada para hacer frente a la pandemia por Covid-19 $9^{41}$, que tenía una vigencia temporal bien delimitada (inicialmente, 30 de septiembre de 2020), aunque ha sido objeto de numerosas modificaciones ulteriores para endurecer o flexibilizar las medidas de contención en función del impacto de la pandemia en el país ${ }^{42}$.

Adicionalmente, hay que señalar que, en los casos de Bulgaria, Hungría, Portugal, Rumanía, y Eslovaquia, las medidas de contención adoptadas se encuadraron en estados de emergencia previstos por la legislación interna - y no por el texto constitucional-, que también dotaban de ciertos poderes extraordinarios al ejecutivo. En el caso de Bulgaria, el estado de emergencia «legislativo» declarado fue creado ex novo para hacer frente a la actual pandemia: así, la expiración del estado de emergencia constitucional vino acompañada de la modificación de la Ley de Salud Pública ${ }^{43}$ a fin de crear el nuevo estado de «condiciones epidemiológicas extraordinarias» —izvunredna epidemiologichna obstanovka_, que fue declarado por

36 Ley 258/2000 Coll, de 14.07.2000, de Protección de la Salud Publica. Disponible, junto a todas sus modificaciones en: https://www.zakonyprolidi.cz/cs/2000-258/zneni-20210427.

37 Ley de Prevención y Control de Enfermedades Infecciosas, de 12.02.2003. Disponible, con todas sus modificaciones, en: https://www.riigiteataja.ee/akt/101072020009; y Ley de Fronteras del Estado, de 30.06.1994. Disponible en: https://www.riigiteataja.ee/akt/108072020007.

38 Ley 1227/2016 de Enfermedades Infecciosas, de 21.12.2016. Disponible en https://finlex.fi/fi/laki/ alkup/2016/20161227).

39 Ley Orgánica 3/1986, de 14 de abril, de medidas especiales en materia de salud pública.

40 Ver, por ejemplo, las modificaciones introducidas en la Ley 1227/2016, de Enfermedades Infecciosas finlandesa, en fechas 29.05.2020 (disponible en https://finlex.fi/fi/laki/alkup/2020/20200400) o 9.07.2020 (disponible en https://finlex.fi/fi/laki/alkup/2020/20200582), que introducían medidas de contención temporales.

41 Leyes n. 7606 and 7607, ambas de 24.06.2020, que fueron refundidas a través de la Ley de 17.07.2020, por la que se introducen una serie de medidas para luchar contra la pandemia por Covid-19 (Disponible, con todas sus modificaciones en https://legilux.public.lu/eli/etat/leg/loi/2020/07/17/a624/jo).

42 Stoppioni, E., The Remains of the Days of Crisis: The Second Wave of Legislative COVID-19 Measures in Luxembourg, VerfBlog, 2021/3/03, https://verfassungsblog.de/the-remains-of-the-days-of-crisis-the-second-waveof-legislative-covid-19-measures-in-luxembourg/

43 Ley de Enmienda y Suplemento de la Ley de Salud, adoptada por la Asamblea Nacional el 12.05.2020. Disponible en: https://dv.parliament.bg/DVWeb/showMaterialDV.jsp?idMat=148005) 
el ejecutivo el 14 de mayo de $2020^{44}$ y ha permitido la gestión de la pandemia en Bulgaria hasta la fecha en que se termina este trabajo sin la necesidad de declarar un nuevo estado de emergencia constitucional ${ }^{45}$ y sin el control parlamentario que éste conllevaría.

En el resto de los Estados miembros indicados, el estado de emergencia «legislativo» existía previamente, aunque su regulación fue —en ocasiones- modificada para adaptarla a las necesidades de la actual pandemia. En Portugal, por ejemplo, la expiración del estado de emergencia constitucional declarado durante la primera ola de la pandemia vino acompañada de la declaración del estado de calamidad al amparo de lo previsto en la existente legislación en materia de protección civil y de vigilancia del sistema de salud pública ${ }^{46}$. Al compás de la mejoría en el número de casos de contaminación por Covid-19 y siguiendo un proceso de desescalada, el estado de calamidad sería sustituido por los estados de contingencia o alerta, que se declararon en distintas partes del territorio a partir del 1 de agosto en función de la situación epidemiológica ${ }^{47}$. El agravamiento de la situación en el país provocó la reintroducción del estado de calamidad el 15 de octubre de $2020^{48}$ y del estado de emergencia constitucional el 9 de noviembre de $2020^{49}$.

En una línea semejante, en Hungría y Eslovaquia la expiración de los estados de emergencia constitucionales vino acompañada, respectivamente, de la declaración del estado de alerta epidemiológica ${ }^{50}$ y del regreso a la situación extraordinaria, que el gobierno eslovaco había declarado ya el 11 de marzo de $2020^{51}$, unos

44 Decisión del Consejo de Ministros n. 325 de 2020, de 14.05.2020, declarando una epidemia excepcional.

45 La declaración de epidemia excepcional ha sido ya extendida hasta en diez ocasiones por el ejecutivo búlgaro (ver las decisiones en https://coronavirus.bg/bg/244), y la última extensión se produjo a través de Decisión del Consejo de Ministros n. 426 de 2021, que extiende la declaración hasta el 31.07.2021.

46 Ver especialmente la Ley n. $.^{\circ} 81 / 2009$, de 21 de agosto, que instituye un sistema de vigilancia de salud pública y la Ley n. ${ }^{\circ}$ 27/2006, de 3 de julio, de Bases de Protección Civil.

47 Desde el 15.07.2020, la declaración del estado de calamidad no se aplicaba a todo el territorio nacional y algunas áreas se encontraban ya bajo un estado de contingencia o alerta (Resolución del Consejo de Ministros n. ${ }^{\circ}$ 51-A/2020). A partir del 1.08.2020, y hasta su reintroducción en octubre de 2020, ninguna parte del territorio se encontraba en estado de calamidad. Para acceder a todas las decisiones del ejecutivo luso al respecto, ir a https://dre.pt/legislacao-covid-19-areas-tematicas\#1

48 Resolución del Consejo de Ministros n. ${ }^{\circ} 88-\mathrm{A} / 2020$, de 14.10.2020.

49 Decreto del Presidente de la República 51-U/2020, de 6 de noviembre de 2020, autorizado por Resolución de la Asamblea Nacional 83-A/2020 de la misma fecha.

50 Decreto del Gobierno de 18.06.2020, declarando el estado de alerta epidemiológica (283/2020. (VI. 17.) Korm. rendelet a járványügyi készülttség bevezetéséröl). La declaración ha sido prorrogada por el ejecutivo hasta en 3 ocasiones y está vigente hasta el 17.12.2021. Todas las prórrogas son accesibles en: https://njt.hu/ jogszabaly/2020-283-20-22.3

51 Resolución del Gobierno eslovaco n. ${ }^{\circ}$ 111, de 11.03.2020, declarando una situación extraordinaria en relación con una emergencia de salud pública de nivel II. Disponible en: https://rokovania.gov.sk/RVL/ Resolution/18249/1. La Resolución del Gobierno eslovaco n. ${ }^{\circ}$ 147/2020, de 10.06.2020, por la que se ponía fin al estado de emergencia constitucional declarado (disponible en: https://www.slov-lex.sk/pravne-predpisy/ SK/ZZ/2020/147/vyhlasene_znenie.html), subrayaba que la declaración de situación extraordinaria continuaba vigente tras la expiración del primero el 13.06.2020. 
días antes de declarar el estado de emergencia constitucional ${ }^{52}$. En ambos casos, se trataba de un estado de emergencia previsto previamente bien en la legislación interna en materia de salud pública —el caso de Hungría ${ }^{33}$ — o en la legislación en materia de protección civil —el caso de Eslovaquia ${ }^{54}$ — , que no requería de la participación del legislador para su declaración o extensión y que se mantuvo vigente hasta la declaración de un nuevo estado de emergencia constitucional en el otoño de 2020 (ver sección II.3). En el caso de Hungría, la legislación correspondiente fue objeto de notables enmiendas a través de la Ley LVIII de 2020 en aras de extender las competencias del ejecutivo durante el estado de alerta epidemiológica, lo que provocó notables críticas ${ }^{55}$.

En Rumanía, la expiración del estado de emergencia dio lugar también a la declaración del estado de alerta, originalmente regulado a través de la Ordenanza de Emergencia Gubernamental (OEG) n. ${ }^{\circ} 21 / 2004$ —aprobada por el Parlamento a través de la Ley n. ${ }^{\circ} 15 / 2005$. Sin embargo, el régimen legal aplicable al estado de alerta fue sustancialmente modificado a través de la Ley n. ${ }^{\circ}$ 55/2020, de 15 de mayo, adoptada tras la decisión del Tribunal Constitucional rumano declarando parcialmente inconstitucional el anterior marco legal ${ }^{56}$. A pesar de controversias relacionadas con la fecha de entrada en vigor de la nueva norma, el estado de alerta fue declarado el 15 de mayo de $2020^{57} \mathrm{y}$, a diferencia de lo ocurrido en Portugal, Hungría y Eslovaquia, ha permitido la gestión de la pandemia y la aplicación de medidas de contención del virus hasta la fecha en que finaliza este trabajo ${ }^{58}$.

52 Resolución Del Gobierno de la República Eslovaca n. ${ }^{\circ}$ 114, de 15.03.2020, sobre la propuesta de declarar el estado de emergencia. Disponible en: https://rokovania.gov.sk/RVL/Resolution/18252/1.

53 Ley CLIV de Salud, de 1997 (disponible en: https://njt.hu/jogszabaly/1997-154-00-00), modificada entre otras por la Ley LVIII, de 18.06.2020, sobre medidas transitorias tras la expiración de la emergencia y el estado de alerta epidemiológica (disponible en https://njt.hu/jogszabaly/2020-58-00-00.0)

54 Ley 42/1994 Z. z. del Consejo Nacional de la República Eslovaca sobre la protección civil de la población. Disponible en: https://www.slov-lex.sk/pravne-predpisy/SK/ZZ/1994/42/20210515.

55 Ley LVIII de 2020, de medidas transitorias para la cesación de una emergencia y la declaración de una alerta epidemiológica. Disponible en: https://njt.hu/jogszabaly/2020-58-00-00.0). Una visión crítica de la misma puede verse en: Halmai, G., Mészáros, G.; Scheppele, K.L.: From Emergency to Disaster: How Hungary's Second Pandemic Emergency will Further Destroy the Rule of Law, VerfBlog, 2020/5/30, https://verfassungsblog.de/from-emergency-to-disaster/; Hungarian Helsinki Committee, Hungarian Civil Liberties Union and Amnesty International Hungary, Never-ending story?, 27.05.2020. Disponible en: https:/helsinki.hu/en/never-ending-story/.

56 Decisión del Tribunal Constitucional rumano n. ${ }^{\circ}$ 157/2020, de 13.05.2020. Disponible en: http:// legislatie.just.ro/Public/DetaliiDocument/225801. Sobre la decisión y sus consecuencias, ver: TANASESCU E-S. y Dima, B., 'The Role of the Romanian Parliament during the COVID-19 Sanitary Crisis. A diminishment of the executive decision-making power', Fondation Robert Schuman, 2020.

57 El estado de alerta fue inicialmente declarado a partir del 15.05.2020, por Decisión del Comité Nacional para Situaciones de Emergencias n. ${ }^{\circ}$ 24/2020, de 14.05.2020, bajo el amparo de la OEG n. ${ }^{\circ} 21 / 2004$. Disponible en: http://legislatie.just.ro/Public/DetaliiDocumentAfis/225276. Una vez entrada en vigor la nueva Ley n. ${ }^{\circ}$ 55/2020 (disponible en: http://legislatie.just.ro/Public/DetaliiDocument/241376), el gobierno declaró nuevamente el estado de alerta a través de la Decisión n. ${ }^{\circ}$ 394/2020, de 18.05.2020.

58 La última decisión extendiendo el estado de alerta fue adoptada por el Comité Nacional para Situaciones de Emergencias el 9.06.2021 (Decisión n. ${ }^{\circ}$ 38) y prevé la vigencia del estado de alerta por un periodo de 30 días a contar desde el 12 de junio. Para acceder a todas las extensiones del estado de alerta, ver: https:// www.mai.gov.ro/utile/ 


\section{El otoño y la sucesiva re-declaración de estados de excepción constitucionales en una parte de los Estados miembros (octubre 2020-junio 2021)}

El otoño de 2020 y el agravamiento de la incidencia de la pandemia en Europa vino acompañada de una re-escalada generalizada en las medidas de contención del virus adoptadas por los Estados miembros de la UE. Nuevamente, cinco de los diez Estados miembros de la UE que decidieron declarar un estado de emergencia constitucional para hacer frente a la primera ola de la pandemia, volvieron a declarar un estado de emergencia constitucional (República Checa, Hungría, Eslovaquia, Portugal y España).

En los Países Bajos, aunque no se declaró un estado de emergencia ex art. 103 (2) de la Constitución nacional, el ejecutivo hizo uso de forma independiente de uno de los poderes extraordinarios que contempla la legislación de desarrollo de ese precepto constitucional ${ }^{59}$ e impuso un toque de queda en todo el país sobre la base del art. 8 (1) y 3 de la Ley de poderes extraordinarios de la autoridad civil $^{60}$, además de las medidas adoptadas sobre la base de lo previsto en la preexistente Ley de Salud Pública y en la Ley temporal adoptada específicamente para hacer frente a la pandemia ${ }^{61}$. La medida adoptada al amparo de la Ley de poderes extraordinarios de la autoridad civil fue inicialmente invalidada por el Tribunal de distrito de La Haya ${ }^{62}$, que consideró que la situación no cumplía las exigencias que requiere el recurso a esa medida extraordinaria - circunstancias excepcionales- y que el gobierno podía haber utilizado los cauces ordinarios para la adopción de la medida - legislación aprobada por el Parlamento. Sin embargo, el Tribunal de Apelación de La Haya llegaría a la conclusión inversa ${ }^{63}$, adoptando

$59 \mathrm{El}$ art. 103 (2) de la Constitución de los Países Bajos, junto con la Ley de 3.04.1996, de coordinación de condiciones excepcionales (disponible en: https://wetten.overheid.nl/BWBR0007981/2018-01-01) regulan los estados de emergencia constitucionales, aunque se permite la activación de los poderes extraordinarios que estos confieren de forma individual en determinadas circunstancias. Ver, al respecto: European Parliamentary Research Service, European Parliament, States of emergency in response to the coronavirus crisis: Situation in certain Member States III, Junio de 2020, pp. 7-8.

60 Reglamento del Ministro de Justicia y Seguridad de 22.01.2021, n. ${ }^{\circ} 3192465$, por el que se establece un toque de queda nacional para luchar contra la epidemia de Covid-19 (disponible en: https://wetten. overheid.nl/BWBR0044738/2021-02-09), adoptado sobre la base de la Ley de 3.04.1996 de poderes extraordinarios de la autoridad civil (disponible en: https://wetten.overheid.nl/BWBR0007982/2021-02-22)

61 Ver Ley de 28.10.2020, por la que se establecen medidas provisionales en conexión con la epidemia de Covid-19 (disponible en: https://wetten.overheid.nl/BWBR0044337/2021-06-01/\#ArtikelI), que modifica, entre otras, la Ley de 9.10.2008, de Salud Pública (disponible en/ https://wetten.overheid.nl/ BWBR0024705/2021-07-01)

62 Tribunal de distrito de La Haya, decisión de 16 de febrero de 2021, caso n. ${ }^{\circ} \mathrm{C} / 09 / 607056$ / KG SAT 21-118. Disponible en https://uitspraken.rechtspraak.nl/inziendocument?id=ECLI:NL:RBDHA:2021:1100

63 Tribunal de Apelación de la Haya, decisión sobre medidas cautelares de 26.02.2021, caso n. ${ }^{\circ}$ 200.290.085/01 (disponible en: https://uitspraken.rechtspraak.nl/inziendocument?id=ECLI:NL:GHDHA: 2021:285). Sobre estos pronunciameinos, ver: Julicher, M. y Vetzo, M., COVID-19 in the Netherlands: of Changing Tides and Constitutional Constants, VerfBlog, 2021/4/22, https://verfassungsblog.de/covid-19-in-thenetherlands-of-changing-tides-and-constitutional-constants/ 
una posición mucho más deferente y validando la utilización de ese poder extraordinario por el ejecutivo.

Más allá del muy específico caso de los Países Bajos, que no puede computarse estrictamente como un supuesto de declaración de un estado de excepción, Eslovaquia fue el primero de los cinco Estados miembros que reintrodujo un estado de emergencia constitucional durante el otoño de 2020 (1 Octubre de $2020^{64}$ ), seguido de la República Checa (5 Octubre $2020^{65}$ ), España (9 de octubre para ciertos territorios, y 25 de octubre de 2020 para el conjunto del territorio nacional ${ }^{66}$ ), Hungría ( 4 noviembre de $2020^{67}$ ) y Portugal (9 de noviembre de $\left.2020^{68}\right)$. La mayoría de esos estados de excepción han expirado ya, aunque estuvieron vigentes durante un periodo más prolongado de tiempo que durante la primera ola, oscilando entre los 5 meses de la República Checa (hasta el 11 de

64 Resolución del Gobierno n. ${ }^{\circ} 587$ de 30.09.2020. El estado de emergencia declarado sobre la base del Art.5 de la Ley Constitucional n. ${ }^{\circ} 227 / 2002$ sobre la seguridad del Estado en tiempos de guerra, estado de guerra, estado de excepción y estado de emergencia, fue prolongado en reiteradas ocasiones. La última prolongación fue adoptada originalmente hasta el 28.05.2021 (Resolución del gobierno de la República eslovaca n. ${ }^{\circ} 215$, del 26.04.2021, accesible en https://www.slov-lex.sk/pravne-predpisy/SK/ZZ/2021/160/20210429). Sin embargo, el gobierno puso finalmente fin al estado de emergencia el 14.05.2021, aunque manteniendo en vigor la situación de emergencia declarada sobre la base de la Ley 42/1994 Z. z., sobre la protección civil de la población (Resolución del gobierno de la República eslovaca n..$^{\circ} 260$, del 14.05.2021, sobre la propuesta de poner fin al estado de emergencia declarado por la Resolución del Gobierno n. 587 de 30.09.2020, accesible en https://www.slov-lex.sk/pravne-predpisy/SK/ZZ/2021/175/20210514).

65 Resolución del gobierno n. ${ }^{\circ} 957$, de 30.09.2020, que fue extendido en reiteradas ocasiones hasta el 14.02.2021. Ante la negativa del Parlamento a prolongar nuevamente el estado de emergencia constitucional, el gobierno decidió declarar un nuevo estado de emergencia constitucional por Resolución n. ${ }^{\circ}$ 125, de 14.02.2021 (disponible en: https://www.vlada.cz/assets/media-centrum/aktualne/nouzovy-stav-0125.pdf). El Parlamento nacional levantó el estado de emergencia por resolución de 18.02.2021 (disponible en: https://www.beck-online. cz/bo/chapterview-document.seam?documentId=onrf6mrqgiyv6obufuya), y esa declaración sería además objeto de un recurso ante el Tribunal Constitucional del país (Pl. ÚS 12/21). Sin embargo, dado el agravamiento de la situación en el país, un cuarto estado de emergencia sería declarado nuevamente el 27.02.2021 y continuó vigente hasta el 11 de abril tras ser extendido el 26.03.2021. Desde entonces, las medidas de contención del virus se basan esencialmente en la Ley n. ${ }^{\circ}$ 94/2021 Coll, de 26.02.2021, de medidas de emergencia para hacer frente a la pandemia por Covid-19 (disponible en https:/www.zakonyprolidi.cz/cs/2021-94/zneni-20210227), parcialmente temporal (28.02.2022) y la Ley n. ${ }^{\circ}$ 258/2000 Coll., de 11.08.2000, de protección de la salud pública, modificada en varias ocasiones durante la pandemia (disponible en: https://www.zakonyprolidi.cz/ cs/2000-258/zneni-20210427). Para un análisis minucioso de la situación, ver: VIKARSKÁ, Z., Czechs and Balances - One Year Later, VerfBlog, 2021/3/30, https://verfassungsblog.de/czechs-and-balances-one-year-later/

66 RD 900/2020, de 9 de octubre, por el que se declara el estado de alarma en ciertos territorios de Madrid (Alcobendas, Alcorcón, Fuenlabrada, Getafe, Leganés, Madrid, Móstoles, Parla and Torrejón de Ardoz), y RD 926/2020, de 25 de octubre, por el que se declara el estado de alarma en todo el territorio. El estado de alarma se prorrogó por RD 956/2020, de 3 de noviembre, hasta el 9.05.2021

67 Decreto del Gobierno 478/2020 (XI.3), declarando el estado de riesgo extremo. Disponible en: https://njt.hu/jogszabaly/2020-478-20-22.1)

68 Decreto del Presidente de la República n. ${ }^{\circ} 51-\mathrm{U} / 2020$, de 6.11.2020, autorizado por Resolución de la Asamblea de la República de n. ${ }^{\circ} 83-\mathrm{A} / 2020$, de 6.11.2020. El estado de emergencia fue prolongado hasta en doce ocasiones con la autorización de la Asamblea nacional, hasta la expiración de la última prolongación del mismo el 30.04.2021 (Decreto del Presidente de la República n. ${ }^{\circ}$ 41-A/2021, de 14.04.2021, por el que se prolonga el estado de alarma, autorizado por Resolución de la Asamblea de la República de n. ${ }^{\circ}$ 114-A/2021, de 14.04.2021 — todos las normas citadas son accesibles en https://dre.pt/legislacao-covid-19-areas-tematicas\#12) 
abril de 2021- aunque con intervalos) y Portugal (hasta el 30 de abril); los 5 meses y medio de Eslovaquia (hasta el 14 de mayo), y los 6 meses de España (hasta el 9 de mayo de 2021). Tan solo el estado de riesgo extremo declarado en Hungría continúa vigente hasta la fecha en que se finaliza este artículo ${ }^{69}$.

En todo caso, la prolongación de los estados de excepción ha suscitado varias controversias relevantes: en el caso de Hungría y República Checa, se han producido sucesivas declaraciones de nuevos estados de emergencia constitucionales, tras la expiración de los anteriores, que podían haber sido prolongados con autorización parlamentaria. Como en ambos casos, el ejecutivo necesitaba de la ayuda del parlamento para prolongar el estado de excepción ya declarado, pero podía declarar en solitario uno nuevo por un periodo breve de tiempo (15 días en Hungría y 30 en la República Checa), surgieron las dudas obvias referidas a la constitucionalidad de la nueva declaración, al entenderse que el ejecutivo pretendía sortear el control parlamentario querido por la Constitución en situaciones de emergencia, como de hecho confirmó el Tribunal Constitucional checo (sección IV).

En el particular caso de Hungría, resulta preocupante también que la prolongación del estado de riesgo extremo por parte del Parlamento no cuente con una fecha de expiración precisa, al indicarse que estará vigente hasta el 15 día posterior al día en que comience la sesión parlamentaria de otoño 2021, fecha que debe ser determinada por la Presidencia de la Cámara.

En la misma línea, aunque sin acercarse a la gravedad de las situaciones mencionadas, llama la atención el excesivo periodo por el que algunos Parlamentos nacionales han autorizado la prolongación de los estados de excepción declarados - véase, el caso de España, en el que la autorización para extender el estado de alarma se hizo por una sola vez y por un periodo de seis meses. Autorizaciones parlamentarias recurrentes por periodos breves de tiempo garantizan un control parlamentario más incisivo sobre las decisiones adoptadas por los ejecutivos en periodos de emergencia constitucional, al permitir a los parlamentos nacionales evaluar la marcha de la crisis y la necesidad de mantener las medidas excepcionales autorizadas, como ya destacara Ackerman ${ }^{70}$.

Finalmente, la prolongación del estado de emergencia declarado durante el otoño también fue problemática en el caso de Eslovaquia, aunque por motivos totalmente distintos. A fin de atajar eventuales prolongaciones abusivas de los estados de excepción, la Ley constitucional 227/2002 Z. z. preveía originalmente

69 Tras la declaración del segundo estado de riesgo extremo el 3.11.2020 (entrada en vigor 4 de noviembre- ver nota a pie n. ${ }^{\circ}$ 67), el Parlamento nacional autorizó la prolongación por un periodo de 90 días (Ley CIX de 2020). El mismo día en que ese estado de riesgo extremo expiraba (8.02.2021), el gobierno volvió a declarar un tercer estado de riesgo (Decreto 27/2021), cuya prolongación sería autorizada por el Parlamento inicialmente hasta el 22.05.2021 (Ley I de 2021) y posteriormente hasta un momento indeterminado en otoño de este año (Ley XL de 2021). Para una información más detallada, ver: Hungarian Helsinki Committee, Emergency regimes in Hungary under the pandemic, Mayo 2021.Disponible en: https://helsinki.hu/en/ wp-content/uploads/sites/2/2021/05/HHC_Hungary_emergency_measures_overview_25052021.pdf)

70 Ackerman, B., «The Emergency Constitution», The Yale Law Journal, n. ${ }^{\circ}$ 113, 2004, pp. 1047-1049. 
la posibilidad de extender el estado de emergencia por un periodo máximo de 90 días ${ }^{71}$. Con el número de infecciones por Covid-19 en pleno aumento y ante la imposibilidad de prorrogar el estado de emergencia declarado el 1 de octubre de 2020 más allá del 29 de diciembre, el ejecutivo propuso la modificación de la ley. El objetivo no era otro que permitir la extensión del estado de emergencia más allá del plazo de 90 días, por periodos adicionales de 40 días, siempre que fuera necesario para hacer frente a la pandemia, y con la correspondiente autorización parlamentaria, sin la cual el estado de emergencia decaería. La modificación fue aprobada el 29 de diciembre, permitiendo así la prolongación del estado de emergencia hasta mayo de 2021.

\section{CARACTERÍSTICAS DE LOS ESTADOS DE EXCEPCIÓN DECLARADOS}

A pesar de que los estados de excepción declarados durante la primavera y el otoño del 2020 en los Estados miembros de la UE presentan elementos diferenciales, algunas características comunes pueden ser identificadas, tal y como veremos en las líneas que siguen.

1. Los elementos esenciales del régimen jurídico aplicable estaban, en general, previstos en la Constitución o la ley de desarrollo, no quedando al arbitrio del ejecutivo

En la mayoría de los Estados miembros de la UE que han declarado estados de excepción, los elementos centrales del régimen aplicable (órgano competente para declararlo, control parlamentario y derechos que pueden ser limitados/suspendidos) aparecían previstos bien en el texto constitucional, bien en la legislación de desarrollo, en línea con las recomendaciones de la Comisión de Venecia ${ }^{72}$. No obstante, hay que señalar que, en algunos de los Estados indicados, la legislación de desarrollo, o incluso el texto constitucional, han sido modificados durante la pandemia, en ocasiones en sentidos preocupantes, y que la actual pandemia ha mostrado alguna laguna relevante en el marco jurídico aplicable.

Ocho de los textos constitucionales de los diez Estados miembros analizados prevén diferentes estados de excepción, regulan las competencias del ejecutivo y el legislativo en relación con su declaración —y su prolongación - y recogen los

71 Ver Articulo 5.2 de la Ley constitucional 227/2002 Z. z., de 11.04.2002, sobre la seguridad del Estado en tiempos de guerra, ley marcial, estado de excepción y estado de emergencia. Disponible en: https:// www.slov-lex.sk/pravne-predpisy/SK/ZZ/2002/227/20201229.html

72 Comisión de Venecia, Report Respect For Democracy, Human Rights And The Rule Of Law During States Of Emergency : Reflections, CDL-AD(2020)014, 19.06.2020, p.5. 
derechos fundamentales que no pueden ser suspendidos durante los estados de excepción (Bulgaria, Estonia, España, Eslovaquia, Hungría, Portugal, Rumanía, República Checa). Se establece así directamente en el texto constitucional —o en leyes constitucionales que lo complementan ${ }^{73}$ - una gradación entre los distintos estados de excepción en función de la gravedad de la crisis a afrontar, de modo que buena parte de esos textos constitucionales prevé un estado de excepción específicamente dirigido a hacer frente a un ataque externo en forma de invasión o guerra (Bulgaria, Estonia, España, Eslovaquia, Portugal, Rumanía, República Checa), asî como otro tipo de estado de excepción dirigido a hacer frente a amenazas internas en forma de revueltas, insurrecciones u otros tipo de amenazas contra el orden constitucional (Estonia, España, Eslovaquia Portugal, Rumanía, República Checa). Adicionalmente, algunos de los Estados analizados prevén específicamente un estado de excepción dirigido a afrontar situaciones de crisis provocadas por desastres naturales o calamidades públicas (Estonia, España, Eslovaquia, Portugal, Rumanía, República Checa), aunque es de reseñar que la determinación de los supuestos de hecho concretos que permiten la declaración de cada uno de esos diferentes estados excepcionales se halla en ocasiones en la ley de desarrollo.

En el caso concreto de Hungría, la tipología de estados excepcionales era mucho más amplia, en tanto la Constitución nacional preveía, antes del comienzo de la pandemia, seis tipos distintos de estados de excepción —crisis nacional, emergencia, defensa preventiva, amenaza terrorista, ataques inesperados, y riesgo extremo- , que han sido recientemente reconducidos a solo tres — estado de guerra, de emergencia y de riesgo ${ }^{74}$ - , aunque la modificación no entrará en vigor hasta el 1 de julio de 2023 .

73 En la República Checa, el texto constitucional apenas hace referencia a las competencias del Parlamento nacional para la declaración del estado de guerra (arts. 39(3) and 43) y es la Ley Constitucional de Seguridad de la República Checa (Ley n. ${ }^{\circ}$ 110/1998 Coll., accesible en https://www.sagit.cz/info/sb98110), junto a la Ley ordinaria de gestión de crisis (Ley n. ${ }^{\circ}$ 240/2000 Coll., accesible en https://www.zakonyprolidi.cz/ cs/2000-240), la que prevé hasta cuatro estados de excepción diferentes — estado de riesgo, de emergencia, de amenaza para el Estado y de guerra. En la República Checa, las leyes constitucionales forman parten del orden constitucional ex art. 112 de la Constitución. En la misma línea, en Eslovaquia, el texto constitucional prevé que una ley constitucional regulará la declaración de guerra, la ley marcial y los estados de excepción y emergencia (arts. 51(2), 102, 119), así como la competencia del tribunal constitucional para pronunciarse sobre la constitucionalidad de los mismos (art. 129 (6)). Esa ley es la Ley constitucional 227/2002 Z. z., de 11.04.2002, sobre la seguridad del Estado en tiempos de guerra, ley marcial, estado de excepción y estado de emergencia (disponible en: https://www.slov-lex.sk/pravne-predpisy/SK/ZZ/2002/227/20201229.html). Sobre ambos casos, ver: European Parliamentary Research Service, Parlamento Europeo, States of emergency in response to the coronavirus crisis: Situation in certain Member States IV, Julio de 2020 (disponible en: http://www.eprs.sso. ep.parl.union.eu/filerep/09-Briefings/2020/EPRS-Briefing-652002-States-of-emergency-Member-StatesIV-FINAL.pdf)

74 La traducción al inglés de la reforma es accesible en Comisión de Venecia, Hungary, Ninth Amendment to the Fundamental Law, CDL-REF(2021)045 (https://www.venice.coe.int/webforms/documents/default. aspx?pdffile $=$ CDL-REF(2021)045-e). La Comisión de Venecia ha emitido ya su opinión al respecto: Hungary - Opinion on the constitutional amendments adopted by the Hungarian parliament in December 2020, adopted by the Venice Commission at its 127th Plenary Session, Venice and online, 2-3 July 2021, CDL$\mathrm{AD}(2021) 029-e$. Disponible en: https://www.venice.coe.int/webforms/documents/?pdf=CDL-AD(2021)029-e 
La regulación constitucional de los Estados indicados se completa, en algunos casos, con el establecimiento de límites temporales concretos aplicables a los estados de excepción (Portugal, Estonia, España, República Checa y Eslovaquia $^{75}$ ), la previsión de la imposibilidad de modificar la Constitución (Estonia, España, Portugal) o de celebrar elecciones (Estonia, Hungría- solo para los estados de crisis nacional y emergencia y las elecciones al parlamento nacional) durante un estado de excepción; o la inclusión de determinadas garantías dirigidas a asegurar el control parlamentario de la declaración del estado de excepción, véase la convocatoria inmediata del parlamento, incluso si no está en sesión (Bulgaria, Portugal, Rumanía, España), la imposibilidad de disolverlo durante un estado de excepción (Estonia, España, Bulgaria, Portugal, Rumanía, Hungríasolo para los estados de crisis nacional y emergencia) o la prórroga del mandato, si no pueden celebrarse elecciones (República Checa, Eslovaquia). El resto de los elementos queda en manos del legislador nacional, al que se exige en ocasiones una mayoría cualificada para la aprobación de la ley de desarrollo (Estonia, España, Hungría, Portugal, Rumanía).

Finlandia y Luxemburgo presentan textos constitucionales más parcos en los que no se establece una tipología o gradación de posibles estados de excepción. En el caso de Finlandia, además de la previsión de un procedimiento específico para adoptar propuestas de derogación de la Constitución (art. 73 de la Constitución), el art. 23 del texto constitucional permite la limitación temporal de derechos fundamentales en situaciones excepcionales, que han de ser definidas por el legislador. En ese sentido, la regulación concreta de los estados de excepción se halla esencialmente en la Ley de Defensa del Estado - Ley 22.7.1991/108376_ y la Ley de poderes de emergencia - Ley 29.12.2011/1552 $2^{77}$ —, esta última empleada durante la pandemia.

En el caso de Luxemburgo, el art. 32 de la Constitución es un poco más detallado, previendo la posibilidad de que el Gran Duque, véase el ejecutivo, legisle en situaciones de crisis internacional, amenazas reales para intereses vitales de toda o parte de la población o peligros inminentes derivados de atentados graves contra la seguridad del país y siempre que el parlamento nacional no pueda adoptar las medidas apropiadas. En tal caso, el Gran Duque puede declarar un estado de crisis, que deberá ser prorrogado por ley aprobada por 2/3 partes de la cámara

75 Los límites temporales no se imponen, sin embargo, en relación con los diferentes tipos de estados de excepción constitucionales, excepto en el caso de Portugal. En Estonia, ex art. 129 de la Constitución, solo se imponen en relación con el estado de emergencia, pero no con el estado de guerra o la situación de emergencia; en España, tan solo se imponen para la declaración inicial del estado de alarma y para el estado de excepción ex art. 116 de la Constitución; en República Checa, ex art. 6 de la Ley Constitucional 110/1998 Coll., tan solo se imponen para la declaración inicial del estado de emergencia; y en Eslovaquia, ex arts. 4 y 5 de la Ley Constitucional 227/2002 Z. z., tan solo para la declaración y prórroga de los estados de excepción y emergencia.

76 Disponible en: https://www.finlex.fi/fi/laki/ajantasa/1991/19911083

77 Disponible en: https://www.finlex.fi/sv/laki/ajantasa/2011/20111552 
de diputados por un plazo máximo de 3 meses. Aunque se hace referencia a la declaración del estado de crisis, el modelo de Luxemburgo se asemeja quizá más al de Bélgica, en la medida en que se atribuyen poderes extraordinarios al ejecutivo no tanto sobre la base de la definición de ciertas situaciones extraordinarias, sino ante la imposibilidad del legislador de hacer frente a tal situación cuando ésta requiere una respuesta inmediata.

No obstante, más allá de las diferencias y similitudes apuntadas hay que destacar que la actual pandemia ha mostrado algunas debilidades de los marcos jurídicos apuntados, desembocando en ocasiones en las correspondientes modificaciones legales o constitucionales, lo que parece ir a contra corriente de la recomendación de la Comisión de Venecia de modificar el marco jurídico aplicable a los estados de excepción en tiempos de normalidad democrática y no durante un período de excepción ${ }^{78}$, recomendación que se ha reiterado al hilo de la modificación constitucional adoptada en Hungría en diciembre de $2020^{79}$.

En Eslovaquia y Estonia, ni el texto constitucional ni la legislación de desarrollo atribuían inicialmente ningún papel al parlamento nacional en relación con la declaración o la prolongación del concreto estado de excepción constitucional utilizado durante la pandemia, debilitándose, tal y como se explicará en la siguiente sección, el control parlamentario del uso de los poderes de excepción por el ejecutivo. Significativamente, esta laguna ha sido colmada durante la pandemia en el caso de Eslovaquia, en tanto la Ley constitucional 227/2002 Z. z fue modificada por Ley constitucional 414/2020 Z. z., de 29 de diciembre de $2020^{80}$, no solo para ampliar el plazo máximo absoluto durante el que el estado de emergencia declarado podía estar vigente — que era de 90 días, como ya se explicó-, sino también para exigir la correspondiente aprobación parlamentaria en relación con cada extensión, que puede ser de un máximo de 40 días.

Aunque la reforma de la legislación aplicable a los estados de excepción no sea recomendable mientras uno de ellos está vigente — como era el caso de Eslovaquia-, hay que señalar que la reforma eslovaca no solo atajaba la laguna referida a la falta de control parlamentario, sino que también daba respuesta a una regulación excesivamente exigente en lo que al plazo máximo de la vigencia de los estados de excepción se refiere: si bien parece recomendable proveer para que cada extensión de un estado de excepción deba realizarse con autorización del parlamento y por periodos limitados de tiempo, quizás no sea conveniente establecer un plazo máximo absoluto de vigencia de la situación excepcional, especialmente cuando la misma busca responder a situaciones críticas que puedan prolongarse en el tiempo — por ej. una pandemia o un conflicto armado.

78 Comisión de Venecia, Report Respect For Democracy, Human Rights And The Rule Of Law During States of Emergency: Reflections, CDL-AD(2020)014, 19.06.2020, p. 5.

79 Comisión de Venecia, Hungary - Opinion on the constitutional amendments adopted by the Hungarian parliament in December 2020, op. cit., pp. 4-5.

80 Disponible en: https://www.slov-lex.sk/pravne-predpisy/SK/ZZ/2020/414/20201229.html 
Adicionalmente, es de reseñar que la Ley constitucional 414/2020 Z. z. eslovaca introducía una cláusula por la que se requiere también aprobación parlamentaria para la declaración de un nuevo estado de emergencia si ésta se produce en menos de 90 días desde la expiración del anterior y se funda en idénticos motivos. El precepto parece claramente dirigido a evitar las situaciones vividas en República Checa y Hungría durante el invierno de 2020, véase el intento del ejecutivo de eludir el control parlamentario sobre las extensiones del estado de excepción por la vía de declarar uno nuevo (ver la sección II.3).

También relacionado con el alcance del control parlamentario sobre el estado de excepción, llama la atención que los textos constitucionales de algunos de los Estados analizados no previeran la limitación de la extensión temporal de las sucesivas prórrogas de los estados de excepción declarados, lo que ha provocado que en algunas ocasiones el parlamento nacional haya autorizado la prórroga del estado de excepción durante periodos prolongados de tiempo — ver la sección II.3. en relación con España- o sin concretar claramente la fecha de finalización de la prórroga - ver la sección II.3. en relación con Hungría ${ }^{81}$. En este sentido, la previsión en el propio texto constitucional del plazo de duración de cada prolongación del estado de excepción, unido a la autorización parlamentaria para tal extensión, tal y como se recoge, por ejemplo, en la Constitución lusa, parece preservar mejor el papel del parlamento durante las emergencias y asegurar un mayor control sobre posibles excesos del ejecutivo.

La gestión de la pandemia también ha planteado dudas en relación con la concreción del marco jurídico que determina las medidas que puede adoptar el ejecutivo una vez declarado el estado de excepción constitucional. En este sentido, es de destacar que algunos de los Estados analizados han introducido modificaciones en la correspondiente legislación de desarrollo a fin de adaptarla a las necesidades de la actual pandemia ${ }^{82}$, en algunas ocasiones con las críticas correspondientes.

En este sentido, resultó controvertida la modificación introducida por el ejecutivo rumano al comienzo de la pandemia en la Ordenanza de Emergencia 1/1999, por la que se regulan los estados de excepción —aprobado por Ley $453 / 2004^{83}$. El gobierno adoptó el 26 de marzo de 2020 y con el estado de emergencia ya declarado, la Ordenanza de Emergencia 34/2020, que modificaba el régimen sancionador aplicable durante el estado de emergencia. La modificación sería anulada poco después por decisión del Tribunal constitucional rumano n. ${ }^{\circ} 152$, de 6 de mayo de $2020^{84}$, que se centraba en la distribución de competencias entre el ejecutivo y el

81 Sobre el debilitado control por el legislador húngaro, ver: KARSAI, D., Can Parliament Exercise Effective Control over the Emergency Legislation?: Comments on the article by Imre Vörös, VerfBlog, 2020/5/21, https:// verfassungsblog.de/can-parliament-exercise-effective-control-over-the-emergency-legislation/

82 Además de las que se citarán en el cuerpo del texto, ver las modificaciones introducidas en Eslovaquia: Ley constitucional 414/2020 Z. z., de 29.12.2020

83 Disponible en http://legislatie.just.ro/Public/DetaliiDocument/241349

84 Disponible en http://legislatie.just.ro/Public/DetaliiDocumentAfis/225555 
legislativo en periodos de emergencia constitucional. El tribunal subrayaba así en su decisión que el ejecutivo se había arrogado una competencia que la constitución atribuía únicamente al legislador, en tanto no podía adoptar ordenanzas de emergencia que afectaran a los derechos fundamentales ex art. 115.6 de la Constitución del país, por lo que procedía declarar inconstitucional la norma en su totalidad.

Mucho más controvertido fue el contenido de la Ley XII de 2020 de protección contra el coronavirus, aprobada por el parlamento húngaro el 30 de marzo de 2020, así como de ciertas reformas ulteriores de la ley de desarrollo del estado de riesgo extremo - Ley CXXVIII, de 2011, de gestión de desastres ${ }^{85}$. La primera introdujo una suerte de carta en blanco por la que el ejecutivo podía suspender la aplicación de leyes, derogarlas o adoptar cualquier otra medida necesaria para asegurar la vida, salud, y propiedad de los ciudadanos y la estabilidad de la economía nacional durante el primer estado de riesgo extremo declarado en la pandemia. Modificaciones ulteriores en la ley de desarrollo de ese estado de excepción han venido a añadir esa posibilidad de forma perenne al listado de medidas extraordinarias que puede adoptar el ejecutivo húngaro una vez declarado el estado de riesgo extremo, contrariando claramente las recomendaciones de la Comisión de Venecia que preconizan un marco jurídico claro, accesible y previsible para los estados de excepción ${ }^{86}$.

\section{Se declararon los estados de excepción menos invasivos, normalmente por un tiempo claramente limitado}

Es de reseñar igualmente, que los Estados miembros de la UE que han declarado un estado de excepción durante la pandemia han recurrido siempre al menos invasivo de los previstos en el texto constitucional, en caso de existir una gradación en la constitución o la ley de desarrollo (Bulgaria, Estonia, España, Eslovaquia, Hungría, Portugal, Rumanía, República Checa). Además, no se ha producido cambio alguno en relación con el tipo de estado de excepción declarado entre la primera ola de la pandemia y el otoño de 2020. La opción elegida podría explicarse en buena parte de los casos porque el estado de excepción correspondiente era el que resultaba aplicable a casos de desastres naturales o calamidades públicas, inclusive crisis sanitarias, epidemias graves o pandemias (Estonia, España, Eslovaquia, Portugal, Rumanía, República Checa).

En otros supuestos, la opción no podía explicarse por la tipología de la crisis a la que se pretendía hacer frente, sino por otros motivos, reseñablemente la

85 Disponible en: https://njt.hu/jogszabaly/2011-128-00-00. La modificación que se comenta afecta al artículo 51/A y fue introducida por la Ley LVIII, de 18.06.2020, por la que se modificó también de forma sustancial el estado de alerta epidemiológica (ver sección II.2). Es de reseñar, no obstante, que la misma norma ha sido modificada hasta en siete ocasiones desde enero de 2020.

86 Ver nota a pie n. ${ }^{\circ} 72$. 
valoración de las autoridades públicas sobre la gravedad de la pandemia. Tal era el caso, por ejemplo, en Portugal, en tanto el art. 19 de la Constitución lusa establece una gradación entre el estado de sitio y de emergencia, señalando que el segundo debe ser declarado en supuestos de menor gravedad, pero sin discriminar entre los motivos que permiten la declaración de uno u otro tipo, que son en cualquiera de los dos casos, una agresión real o inminente por parte de fuerzas extranjeras, una amenaza grave de perturbación del orden constitucional democrático, o una calamidad pública.

En todo caso, es de reseñar que la opción por uno u otro tipo de estado de excepción ha sido cuestionada en algunos Estados miembros, significativamente en España, donde el Tribunal Constitucional acaba de declarar la nulidad parcial del decreto por el que se declaró el primer estado de alarma en el entendimiento que el tipo de estado de excepción utilizado no permitía la suspensión del derecho a la libertad personal y que, por tanto, para confinar al conjunto de la población era necesario haber acudido al estado de excepción, el segundo en gravedad de los tres estados excepcionales previstos en el texto constitucional español ${ }^{87}$.

Además de optar por el estado de excepción potencialmente menos intrusivo o lesivo de los derechos fundamentales, en línea con las recomendaciones de la Comisión de Venecia, cabe también reseñar que la mitad de los Estados miembros analizados utilizaban este recurso constitucional por primera vez (Bulgaria, Estonia, Rumanía, Finlandia, Portugal). La otra mitad habían declarado previamente ese tipo de estado de excepción (Hungría, España, Luxemburgo, República Checa, Eslovaquia), aunque normalmente lo habían hecho en contadas ocasiones, para una parte del territorio y como consecuencia de un desastre natural (Hungría o República Checa) o para hacer frente a una situación de paralización de servicios considerados esenciales (España, Eslovaquia) ${ }^{88}$. El escaso uso previo de esta herramienta puede explicar buena parte de las dudas jurídicas surgidas durante su aplicación en la pandemia.

Finalmente, cabe destacar también que los estados de excepción declarados lo han sido, con carácter general, por periodos limitados de tiempo, en línea con las recomendaciones de la Comisión de Venecia sobre la temporalidad de las medidas adoptadas en situaciones excepcionales. Tal y como se señaló en las secciones II.1 y II.3 de este trabajo, la temporalidad de las medidas adoptadas bajo los estados de excepción declarados solo ha planteado problemas en los casos de Hungría y, quizás también, de España, en la medida en que la prórroga del tercer estado de alarma español se hizo de una sola vez y por un periodo excesivo de tiempo — seis meses. En el resto de los casos, y tal y como se explicará con detalle en la sección

87 STC 72/2021, de 14 de julio.

88 Sobre la situación en cada Estado miembro, ver la serie de estudios publicada por el Parlamento Europeo sobre la pandemia: States of emergency in response to the coronavirus crisis: Situation in certain Member States I, II, III y IV, EPRS, Parlamento Europeo, 2020. 
siguiente, los estados de emergencia han sido declarados o prorrogados por periodos de tiempo claramente delimitados y normalmente breves.

\section{CONTROL PARLAMENTARIO SOBRE LA DECLARACIÓN Y PRÓRROGA DE LOS ESTADOS DE EXCEPCIÓN}

Además de exigir una regulación de los estados de excepción que sea clara, accesible y previsible, actuando de escudo frente a posibles abusos del ejecutivo, y de exigir que las medidas adoptadas sean necesarias, proporcionadas y limitadas en el tiempo, la Comisión de Venecia ha insistido en la necesidad de que exista un control parlamentario adecuado de las decisiones adoptadas por el ejecutivo durante los estados de excepción, una cuestión que ha sido el foco de no pocos estudios a lo largo de la presente pandemia ${ }^{89}$.

Como veremos en las siguientes páginas, los parlamentos nacionales de los Estados miembros de la UE han participado en la toma de decisiones referida a la declaración y prórroga de los estados de excepción declarados salvo en casos tasados, y ello a pesar de que en muchas ocasiones adoptaron tales decisiones en medio de medidas severas de confinamiento y utilizando mecanismos decisorios extraordinarios puestos en marcha para garantizar la continuidad, aunque solo fuere parcialmente, de la actividad parlamentaria. Sin embargo, una vez declarado el estado de excepción correspondiente, ha sido el ejecutivo el que ha liderado la toma de decisiones sobre las medidas concretas a adoptar para frenar la pandemia en cada uno de sus estadios, limitándose la actividad parlamentaria a la valoración de las decisiones gubernamentales mediante los mecanismos habituales de control parlamentario o, en el mejor de los casos, mediante su aprobación a posteriori.

\section{Un control parlamentario relevante sobre la declaración o la prórroga de los estados de excepción}

Tal y como se indicaba anteriormente y a diferencia de lo que ha ocurrido en relación con la declaración de los estados de emergencia «legislativos» a los que

89 Entre otros: Barcelo Rojas, D. y otros (coods.), Covid 19 y parlamentarismo. Los Parlamentos en cuarenta. Instituto de Investigaciones Juridicas, UNAM, 2020; VV.AA., Special Issue on Legislatures in the time of Covid-19, The Theory and Practice of Legislation, vol. 8, 2020; Murphy, J., Parliaments and Crisis: Challenges and Innovations. Parliamentary Primer No 1, International Institute for Democracy and Electoral Assistance (IDEA), 2020. Ver también los estudios sobre un notable numero de países publicados en la página web de la Inter-Parliamentary Union, Country compilation of parliamentary responses to the pandemic (disponible en: https:// www.ipu.org/country-compilation-parliamentary-responses-pandemic) y de la Fondation Schumann, The impact of the health crisis on the functioning of Parliaments in Europe (disponible en: https://www.robert-schuman. eu/en/doc/ouvrages/FRS_Parliament.pdf) 
nos referíamos en la sección II.2 de este trabajo ${ }^{90}$, la mayoría de los parlamentos nacionales ha participado bien en la declaración o la prórroga de los estados de excepción ligados a la pandemia. A pesar de que la pandemia, especialmente durante la primera ola, puso bajo notable presión a todas las instituciones parlamentarias, que se vieron obligadas en ocasiones a modificar sus procedimientos de discusión y adopción de decisiones para mantener la actividad parlamentaria a la par que protegían la salud de los parlamentarios y de sus trabajadores ${ }^{91}$, los parlamentos de los Estados miembros que declararon un estado de excepción tuvieron que reunirse para pronunciarse bien sobre su declaración o su prórroga, en función de lo previsto en el ordenamiento interno. Las únicas excepciones fueron los parlamentos eslovaco y estonio, en tanto ninguno de los dos tenía atribuidas competencias en relación con la declaración o prórroga de los estados de excepción utilizados durante la primera ola de la pandemia ${ }^{92}$. No obstante, tal laguna fue llenada durante la segunda ola en relación con el parlamento eslovaco, tal y como ya se detalló.

En relación con el resto de los Estados miembros, es de destacar que el papel de los parlamentos nacionales ha seguido dos modelos: bien han declarado o autorizado la declaración del estado de excepción correspondiente (control ex ante), bien ha intervenido ex post, tras la declaración del estado de excepción por el ejecutivo. Tan solo los parlamentos de Bulgaria, Finlandia y Portugal tenían atribuida la competencia de bien declarar (art. 84 de la Constitución búlgara), bien aprobar la declaración (art. 138 de la Constitución portuguesa, art. 6 de la Ley finlandesa de poderes de emergencia) del estado de emergencia. En el caso finlandés, el art. 7 de la Ley de poderes de emergencia permite la entrada en vigor inmediata del decreto que delimita el alcance del estado de emergencia en situaciones urgentes. Pero esta posibilidad no fue utilizada y el Parlamento aprobó la propuesta presentada por el ejecutivo en el corto plazo de 2 días ${ }^{93}$.

Los controles ex-post se produjeron bien en relación con la propia declaración del estado de excepción, bien en relación con su prórroga. En Rumanía, el parlamento ha de aprobar la declaración del estado de emergencia en un plazo de 5 días desde su aprobación por el ejecutivo (art. 93.1 de la Constitución rumana),

90 M. Diaz Crego y S. Kotanidis, op. cit., pp. 38-40, en el que se explica que tan solo los parlamentos alemán, francés y letón han participado en la toma de decisiones en relación con la declaración o prórroga de los regímenes legales declarados en sus países.

91 Además de los estudios referidos en la nota a pie 89, ver: Diaz Crego, M. y Manko, R., Parliaments in emergency mode. How Member States' parliaments are continuing with business during the pandemic, EPRS, Parlamento Europeo, 2020.

92 N. Atanassov, H. Dalli, C. Dumbrava, y otros, States of emergency in response to the coronavirus crisis: Situation in certain Member States II, EPRS, European Parliament, Mayo 2020, p. 6; Z. AlexANDre, M. Del Monte, G. ECKerT, y otros, States of emergency in response to the coronavirus crisis: Situation in certain Member States IV, EPRS, European Parliament, Julio 2020, p. 11.

93 Murphy, J., op. cit., p. 33-34. 
mientras que en la República Checa el parlamento puede anular la declaración del estado de emergencia tras su adopción por el ejecutivo, tal y como de hecho ocurrió en relación con el tercer estado de emergencia declarado durante la pandemia $^{94}$. Adicionalmente, en todos los Estados miembros que declararon un estado de emergencia constitucional, salvo Estonia —y Eslovaquia, durante la primera ola de la pandemia-, el parlamento debe aprobar la prórroga del estado de excepción transcurrido un periodo más o menos breve de tiempo desde su declaración inicial — por ej. 10 días en Luxemburgo, 15 días en España, Portugal y Hungría. Plantea quizás alguna duda el plazo de 30 días en el que el parlamento checo debe pronunciarse sobre la prórroga del estado de emergencia. Sin embargo, puesto que el parlamento tiene atribuida la competencia de pronunciarse sobre la declaración, anulándola si lo considerara oportuno, antes de pronunciarse sobre la prórroga, el control de las decisiones gubernamentales es posible antes de ese plazo.

En esta lógica, parece poder afirmarse que el control parlamentario sobre la toma de decisiones en relación con la pandemia se ha producido bien ex-ante (en casos contados) o ex-post, pero en este segundo supuesto el plazo transcurrido entre la declaración y la toma de postura del parlamento ha sido más o menos breve y, en ningún caso, superior a los 30 días (República Checa), lo que parece adecuarse razonablemente bien a las recomendaciones de la Comisión de Venecia que exige un control parlamentario relevante sobre las medidas de excepción, pero admitiendo la posibilidad de que este se produzca a posteriori, en el entendimiento de que la situación puede requerir medidas tan urgentes que no se adecuen a los tiempos parlamentarios.

\section{Un control parlamentario sobre los estados de excepción que ha sido normalmente periódico y a intervalos más o menos breves de tiempo}

Es de señalar, adicionalmente, que salvo algunas excepciones relevantes, las prórrogas de los estados de excepción declarados se ha producido por periodos más o menos breves de tiempo, asegurando un control parlamentario periódico sobre las medidas adoptadas y sobre la necesidad y oportunidad de mantenerlas. Durante la primera ola de la pandemia, las prórrogas se produjeron con carácter general por periodos limitados de tiempo de entre 15 días (España y Portugal) a 1 mes y medio (Finlandia) ${ }^{95}$, lo que permitió a los parlamentos nacionales verificar en reiteradas ocasiones si la situación continuaba requiriendo del uso de poderes de excepción. Las únicas excepciones fueron Luxemburgo, donde solo se produjo una prórroga del estado de crisis por un

94 Ver nota a pie n. ${ }^{\circ} 65$.

95 Diaz Crego, M. y Kotanidis, S., op. cit., pp. 32-38. 
periodo de 3 meses, y Hungría, donde la prórroga del estado de riesgo extremo se autorizó sine die, tal y como se analizó en la sección II.1 de este trabajo.

Las prórrogas de los estados de excepción declarados en otoño de 2020 han planteado más dudas, no solo porque los ejecutivos de varios Estados miembros - República Checa y Hungría - han intentado impedir el correspondiente control parlamentario por la vía de re-declarar un nuevo estado de excepción tras la expiración del anterior, sino también porque algunas prórrogas se han producido sin una limitación clara de tiempo - Hungría - o por periodos de tiempo excesivamente largos —España-, impidiendo un control periódico sobre la gravedad de la situación y la necesidad de mantener el estado de excepción y debilitando la posición del parlamento, tal y como ya se señalara en la sección II.3 de este trabajo. Es de destacar, no obstante, que en Portugal, República Checa y Eslovaquia, las prórrogas de los estados de excepción declarados durante el otoño de 2020 se ha seguido produciendo por intervalos de tiempo que han oscilado entre los 15 días de Portugal y los 40 días de Eslovaquia, en línea con los postulados de la Constitución de emergencia de Ackerman ${ }^{96}$.

\section{Un control parlamentario poco incisivo en relación con las medidas concretas aprobadas por el ejecutivo en uso de los poderes de excepción}

Finalmente, habría que reseñar que, si bien el marco jurídico aplicable a los estados de excepción declarados por los Estados miembros de la UE durante la pandemia atribuía un papel relevante a los parlamentos nacionales en relación con la declaración y la prórroga de los estados de excepción, y que ese papel conllevaba la facultad de delimitar desde el punto de vista material y territorial los poderes atribuidos al ejecutivo en esta situación de crisis, una vez declarados esos estados de excepción, los ejecutivos han liderado la adopción de las medidas concretas a aplicar para contener la pandemia en cada momento, con una escasa participación del legislativo.

Salvo en los escasos supuestos en los que el marco jurídico aplicable a los estados de excepción preveía algún tipo de control parlamentario sobre los decretos adoptados por el ejecutivo en uso de sus poderes de excepción ${ }^{97}$, el papel del

96 Ackerman, B., «The Emergency Constitution», op. cit., pp. 1047-1049.

97 Véase, por ejemplo, el art. 10 de la Ley finlandesa de poderes de emergencia que exige que cada decreto o decisión adoptado sobre la base de los poderes de emergencia atribuidos al ejecutivo sea sometido al parlamento de forma inmediata y sea derogado si el parlamento lo decide. Igualmente, véase el art. 1.2. de la Ley de 3.04.1996 de poderes extraordinarios de la autoridad civil holandesa, que permite el uso individual de ciertos poderes excepcionales y que fue utilizada durante el otoño de 2020. Esa norma prevé que, en caso de adoptarse un RD haciendo uso de tales poderes excepcionales, el ejecutivo deberá remitir al parlamento un proyecto de ley sobre el mantenimiento de tal medida. Como último ejemplo, véase el art. 105 de la Constitución belga, que permite al parlamento del país delegar competencias legislativas en el ejecutivo bajo circunstancias excepcionales y que ha sido interpretado por el Consejo de Estado del país en el sentido de exigir, 
parlamento se ha reducido al mero control de las medidas adoptadas por el gobierno a través de los mecanismos ordinarios de control parlamentario ${ }^{98}$. En ocasiones, esos mecanismos han sido reforzados por la imposición de una obligación expresa al ejecutivo de mantener regularmente informado al parlamento sobre las medidas adoptadas en el marco de la crisis; obligación impuesta bien por el propio Derecho de excepción ${ }^{99}$ o por la resolución declarando el correspondiente estado de excepción ${ }^{100}$.

A pesar de ello y a la luz de la duración de esta crisis, cabría reflexionar sobre una participación del parlamento nacional que fuera más incisiva, especialmente en relación con aquellas medidas que supongan una clara limitación de los derechos fundamentales de los ciudadanos, en línea, por ejemplo, con lo propuesto por Ackerman en su Constitución de emergencia — creación de una comisión específica de control del ejercicio de los poderes de excepción; liderada por la minoría parlamentaria y con pleno acceso a toda la información pertinente en manos del ejecutivo - o con aquellos modelos europeos que exigen la aprobación parlamentaria ulterior de las medidas adoptadas durante el estado de excepción que supongan una invasión de las competencias del parlamento ${ }^{101}$.

\section{CONTROL JUDICIAL DE LA DECLARACIÓN Y PRÓRROGA DE LOS ESTADOS DE EXCEPCIÓN}

Al igual que se ha indicado en relación con el control parlamentario de las medidas de excepción, la Comisión de Venecia también ha reseñado en reiteradas ocasiones que el poder judicial juega un papel muy relevante a la hora de evitar posibles excesos del ejecutivo. A ojos del organismo internacional, el poder judicial ha de jugar un papel relevante no solo en relación con el control de la legalidad/ constitucionalidad de la declaración - y eventuales prórrogas- del correspondiente estado de excepción, sino también en relación con el control de la legalidad, necesidad y proporcionalidad de cada una de las medidas adoptadas.

entre otras cosas, un control parlamentario a posteriori sobre cada uno de los decretos de poderes especiales aprobados por el ejecutivo sobre la base de la delegación, al menos cuando supongan el ejercicio de competencias constitucionalmente atribuidas al legislador (Consejo de Estado, Sección Legislativa, Avis 47.062/1.V, 18 Agosto de 2009, punto 2.4.1).

98 Diaz Crego, M. y Kotanidis, S. op. cit., pp. 46-48.

99 Por ejemplo, el art. 18.5 de la Ley sobre los Estados de Emergencia de Estonia (Disponible en https://www.riigiteataja.ee/en/eli/ee/530122013002/consolide/current) prevé la obligación de informar al parlamento sobre las medidas adoptadas una vez declarado éste.

100 Por ejemplo, en España, el punto 3..$^{\circ}$ de la Resolución de 25.03.2020, del Congreso de los Diputados, por la que se ordena la publicación del Acuerdo de autorización de la prórroga del estado de alarma declarado por el RD 463/2020, de 14 de marzo, modificaba el RD 463/2020, de 14 de marzo, declarando el primer estado de alarma a fin de imponer al ejecutivo la obligación de informar semanalmente al Congreso sobre las medidas adoptadas.

101 Ver nota a pie n. ${ }^{\circ} 97$. 
La valoración del papel del poder judicial de los Estados miembros en lo que se refiere al control de cada una de las medidas adoptadas durante los correspondientes estados de excepción queda lejos de las pretensiones de este artículo, en la medida en que la aplicación de las mismas es objeto de control — normalmentepor los tribunales ordinarios y ha sido fuente de una litigiosidad notable ${ }^{102}$. Piénsese que, solo en España, una primera búsqueda en la base de datos del poder judicial utilizando como palabra clave «estado de alarma» ofrece el llamativo número de más de 16.000 decisiones judiciales adoptadas entre marzo del 2020 y el momento en que se escribe este artículo. Una cifra que impide un análisis detallado en estas líneas, especialmente si se extiende a los 10 Estados miembros que han utilizado el Derecho de excepción durante la presente pandemia. Sin embargo, el número de decisiones judiciales en las que se valora la constitucionalidad de modificaciones en la ley de desarrollo de los estados de excepción o de la declaración de un estado de excepción o su prórroga es mucho más reducido ${ }^{103}$, permitiendo una primera valoración.

El Tribunal Constitucional rumano ha sido el único que se ha pronunciado hasta la fecha sobre la constitucionalidad de modificaciones introducidas en el marco legal de los estados de excepción durante la pandemia, aunque también ha jugado un papel relevante en relación con el control de medidas concretas de contención adoptadas por el ejecutivo tanto en el marco del estado de emergencia como del régimen legal que le siguió ${ }^{104}$. No obstante, por lo que ahora nos interesa, hay que destacar que el tribunal constitucional rumano hubo de resolver el recurso de inconstitucionalidad interpuesto por el Defensor del Pueblo del país contra la Ordenanza de Emergencia n. ${ }^{\circ} 34 / 2020$, por la que se modificó el régimen jurídico aplicable a los estados de excepción al principio de la pandemia a fin de incrementar las multas que podían imponerse en caso infringir las ordenanzas militares adoptadas al amparo del estado de emergencia. En su decisión, el Tribunal Constitucional dejó claro que el ejecutivo no podía restringir derechos fundamentales a través de ordenanzas de emergencia y que esta competencia le correspondía únicamente al legislador, incluso una vez declarado un estado de excepción, lo que conllevó la declaración de nulidad de la norma cuestionada ${ }^{105}$. El tribunal fortalecía así el papel del parlamento durante

102 No obstante, algunas sentencias especialmente reseñables valorando la legalidad, necesidad y proporcionalidad de las medidas adoptadas en los Estados miembros de la UE puede verse en: Comisión de Venecia, Interim report on the measures taken in the EU Member States as a result of the Covid-19 Crisis and their impact on Democracy, the Rule of Law and fundamental Rights, CDL-AD (2020)018, 8-9 October 2020.

103 Además de las que se citarán en el cuerpo del texto, podrían encajar también en esta misma noción las sentencias de los tribunales holandeses citadas en la sección II. 3 de este trabajo.

104 Para más detalles, ver: Selejan-Gutan, B. Romania in the Covid Era: Between Corona Crisis and Constitutional Crisis, VerfBlog, 2020/5/21, Disponible en https://verfassungsblog.de/romania-in-the-covidera-between-corona-crisis-and-constitutional-crisis/

105 Decisión del Tribunal constitucional rumano n. ${ }^{\circ}$ 152, de 6.05.2020, Disponible en http://legislatie.just.ro/Public/DetaliiDocumentAfis/225555 
la pandemia, reforzando los contrapesos que impiden al ejecutivo abusar del poder en períodos de emergencia.

Mas allá de este elemento esencial de la sentencia, en un llamativo obiter dictum, el tribunal constitucional aportaba su comprensión de los decretos presidenciales por los que se declara el estado de emergencia, indicando que son actos administrativos del Presidente en relación con el parlamento que, ex artículo 126.6 de la Constitución rumana, estarían excluidos de control judicial. A ojos del tribunal, el control de tales actos vendría dado por su necesaria aprobación parlamentaria - 5 días después de la aprobación - y por el posible control de constitucionalidad de esa decisión del parlamento. Ese entendimiento de los decretos de declaración de los estados de emergencia, que parece excluirlos de todo control judicial directo, ha sido criticado por la doctrina ${ }^{106}$ y fue objeto de un voto concurrente ${ }^{107}$.

Además de esta decisión, hay que señalar que varios tribunales de los Estados miembros de la UE se han pronunciado sobre la legalidad/constitucionalidad de los decretos de declaración de los estados de excepción o sus prórrogas. Más allá de la decisión del Tribunal Constitucional español referida a la constitucionalidad del estado de alarma declarado en España en marzo de 2020, todavía no publicada en el momento en que se terminan estas líneas, tan solo los tribunales constitucionales de la República Checa y Eslovaquia se han pronunciado directamente sobre esta cuestión y su pronunciamiento muestra, en línea con el obiter dictum de la sentencia del Tribunal Constitucional rumano que acabamos de citar, las dificultades que conlleva la valoración de las condiciones sustantivas que permiten la declaración de estos estados excepcionales.

El Tribunal Constitucional checo se ha pronunciado en varias ocasiones sobre las sucesivas declaraciones de estados de emergencia en el país durante la pandemia y las medidas adoptadas en el marco de los mismos. Sin embargo, su entendimiento de tales decisiones quedaba reflejado ya en la inicial Pl. ÚS 8/20, de 28 de abril de 2020, en la que se pronunció sobre la constitucionalidad de la primera declaración del estado de emergencia en el país y algunas de las medidas de emergencia adoptadas por el ejecutivo ${ }^{108}$. La controvertida decisión traía causa del recurso presentado por un particular el 26 de marzo de 2020 y se adoptaba antes de la expiración del estado de alarma, mostrando la agilidad del Tribunal Constitucional a la hora de resolver sobre la materia. El Tribunal, dividido a la mitad sobre el sentido de su decisión -8 magistrados votaron a favor y 7 en con-

106 TĂNĂSESCU E.-S. y DimA B. 'The Role of the Romanian Parliament during the COVID-19 Sanitary Crisis. A diminishment of the executive decision-making power', Fondation Robert Schuman, 2020, p. 4-5; SELEJAN-GUTAN, B. Romania in the Covid Era: Between Corona Crisis and Constitutional Crisis, VerfBlog, 2020/5/21 Disponible en https://verfassungsblog.de/romania-in-the-covid-era-between-corona-crisis-and-constitutional-crisis/).

107 Ver las opiniones concurrentes de las jueces Simina-Elena Tanasescu y Livia-Doina Stanciu a la Decisión del Tribunal constitucional rumano n. ${ }^{\circ}$ 152, de 6.05.2020.

108 Disponible en https://www.usoud.cz/fileadmin/user_upload/Tiskova_mluvci/Publikovane_nalezy/ 2020/Pl._US_8_20_vcetne_disentu_na_web.pdf 
tra-, rechazaba los argumentos del demandante y concluía que las decisiones del ejecutivo declarando un estado de emergencia, en la medida en que no contengan ninguna medida excepcional concreta, no son susceptibles de revisión por el Tribunal Constitucional. El Tribunal explicaba su decisión subrayando que el ordenamiento interno no preveía ningún mecanismo concreto de control judicial de esas declaraciones y que las mismas debían considerarse actos de gobierno de naturaleza política, sometidos al control político del parlamento, pero excluidas de control judicial. El tribunal solo las entendía revisables en supuestos excepcionales, véase si el tribunal entendiera que el acto por el se declara el estado de emergencia es contrario a los principios fundamentales de un Estado democrático de Derecho, supone un cambio en los elementos esenciales del mismo o contraviene las obligaciones internacionales contraídas por el país (par. 27). Adicionalmente, el Tribunal Constitucional dejaba claro en su pronunciamiento que las resoluciones del ejecutivo adoptadas en el marco del estado de emergencia debían considerarse actos normativos, lo que tenía un impacto sobre la legitimación para recurrirlos ante el propio tribunal constitucional, en tanto vedaba la presentación de recursos por particulares, limitando la legitimación activa a demandantes privilegiados.

A pesar de la limitación de la legitimación activa para acudir al tribunal, éste ha tenido que pronunciarse sobre otras decisiones gubernamentales adoptadas en el marco de los estados de emergencia ${ }^{109}$ y sobre otras declaraciones - y prórrogas - de los estados de emergencia, especialmente del tercero declarado por el ejecutivo ${ }^{110}$, que hay que recordar, fue declarado tras la expiración del anterior y ante la imposibilidad de lograr la necesaria autorización parlamentaria para la prórroga. Sin embargo, buena parte de los recursos han sido inadmitidos por cuestiones procesales y, en lo que se refiere a las declaraciones y prórrogas de los estados de emergencia, el Tribunal constitucional checo ha reiterado su deferente jurisprudencia marcando una línea roja tan solo en relación con los elementos formales del estado de emergencia: en su decisión referida al tercer estado de emergencia, el Tribunal Constitucional dejaba claro que el gobierno no podía evitar el control parlamentario sobre la prórroga del estado de excepción por la vía de declarar un nuevo estado de emergencia ${ }^{111}$, pronunciamiento que reforzaba la posición del parlamento en periodos de excepción, asegurando los necesarios con-

109 Entre las más relevantes, y además de las que se citan en la nota a pie siguiente, ver: Decisión del Tribunal Constitucional checo de 29.06.2021, Pl.ÚS 22/21 (prohibición de prestación de servicios y cierre de comercios, salvo en ciertos supuestos); Sentencia del Tribunal Constitucional checo de 9.02.2021, Pl. ÚS 106/20 (prohibición de prestación de servicios y cierre de comercios, salvo en ciertos supuestos); Resolución de 16.03.2021, Pl.ÚS 16/21. Todas las decisiones están disponibles en: https://www.usoud. cz/vyhledavani-rozhodnuti-us

110 Sentencia del Tribunal Constitucional checo de 12.05.2020, Pl. ÚS 11.20; Resolución del Tribunal Constitucional de 16.03.2021, Pl. ÚS 12/21; Resolución 2.03.2021, Pl.ÚS 5/21; Resolución de 2.03.2021, Pl.ÚS 9/21; Resolución de 2.03.2021, Pl.ÚS 10/21.

111 Ver, Resolución del Tribunal Constitucional de 16.03.2021, Pl. ÚS 12/21. 
trapesos frente al ejecutivo. Aun así, la deferencia mostrada por la jurisprudencia constitucional checa hacia las decisiones del ejecutivo referidas a la declaración de un estado de emergencia es más que evidente.

En una línea semejante, el Tribunal Constitucional eslovaco se pronunció también sobre la constitucionalidad del estado de emergencia declarado en octubre de 2020 a raíz de un recurso presentado por la Fiscalía y un grupo de diputa$\operatorname{dos}^{112}$. En una decisión unánime, adoptada apenas una quincena de días después de la declaración del estado de emergencia, el Tribunal constitucional concluyó que la declaración se adecuaba a lo previsto en el texto constitucional y la legislación de desarrollo.

Era la primera ocasión en que el tribunal hacía frente a un recurso contra la declaración de un estado de excepción, tal y como prevé expresamente el art. 129 del texto constitucional del país. En esta lógica, el tribunal trató de delimitar el estándar de revisión de la decisión impugnada, subrayando que su competencia se extendía tanto a la revisión de los motivos que permiten la declaración del estado de emergencia según la normativa interna — condiciones materiales-, como a los elementos formales de tal decisión. A pesar de la extensión de su competencia revisora, el tribunal reconocía que la decisión sobre si procede o no declarar un estado de emergencia no solo exige un criterio experto, sino también una decisión política, y que el ejecutivo está en mejor posición que el propio tribunal para valorar esas motivaciones, dado su vínculo democrático con la ciudadanía. En ese sentido, el tribunal entendía que solo debía valorar la racionalidad de la decisión gubernamental y que esta encajara razonablemente en los elementos fácticos que permiten la declaración del estado de emergencia según la normativa interna. El Tribunal subrayaba así que solo cuando fuera manifiestamente desproporcionada procedería la declaración de inconstitucionalidad de la decisión gubernamental.

A la luz del estándar fijado y teniendo en cuenta que el gobierno había valorado la situación epidemiológica del país, el tribunal constitucional consideraba cumplidas las exigencias derivadas del texto constitucional, aunque desde el punto de vista formal subrayaba varias deficiencias — que no consideraba suficientes para declarar la nulidad_-, véase la falta de motivación expresa de la propia declaración del estado de emergencia, así como la inadecuada concreción del ámbito territorial de aplicación del mismo. A pesar de estas indicaciones formales, el tribunal se mostraba claramente deferente hacia el ejecutivo, otorgándole un amplio margen de apreciación a la hora de determinar si concurrían o no las condiciones materiales para declarar el estado de excepción.

En esta lógica, tanto el Tribunal Constitucional eslovaco, como el checo, parecían reconocer la dificultad de juzgar la adecuación de la declaración de un estado de excepción desde una perspectiva sustantiva, apuntando que salvo para

112 Sentencia del Tribunal constitucional eslovaco de 14.10.2020, PL. ÚS 22/2020-104. 
los casos de manifiesta inconstitucionalidad o desproporción, ese control debe quedar en manos del parlamento. Sin embargo, su posicionamiento parecía distinto en relación con el control del procedimiento y la salvaguarda del rol del parlamento, perfilando en esos supuestos un estándar de control menos deferente, en línea con los propuesto por Ackerman en su Constitución de emergencia ${ }^{113}$.

\section{A MODO DE CONCLUSIÓN.}

El uso del Derecho de excepción en los Estados miembros de la Unión Europea durante la pandemia ha sido bastante extenso. Como refleja el análisis realizado, durante la primera ola de la pandemia diez Estados miembros declararon un estado de excepción constitucional (Bulgaria, República Checa, Estonia, Finlandia, Hungría, Luxemburgo, Portugal, Romania, Eslovaquia, España), mientras que el resto prefirió hacer uso de instrumentos estrictamente legislativos para adoptar las correspondientes medidas de contención del virus. Esa cifra se vio reducida a 5 Estados miembros durante el otoño de 2020 (Eslovaquia, República Checa, España, Hungría y Portugal).

El análisis del Derecho de excepción en el conjunto de los 27 Estados miembros muestra que la mayoría de los Estados cuyos textos constitucionales contenían un estado de emergencia constitucional adaptado a la situación de pandemia decidieron declararlo — con las excepciones claras de Polonia, Croacia y Países Bajos-; que los que lo hicieron optaron por el estado de excepción menos invasivo de los previstos en la constitución nacional; aseguraron el carácter temporal del estado de excepción, imponiendo claros límites temporales a su declaración y prórroga(s), salvo en el caso de Hungría; sometieron las ulteriores prórrogas al correspondiente control parlamentario, salvo en el caso de Estonia y Eslovaquia - en este caso, tan solo durante la primera ola de la pandemia; y; en algunos casos, el poder judicial o el tribunal constitucional ejerció cierto control sobre la declaración o prórroga de los estados de excepción, significativamente en aras de salvaguardar las prerrogativas del parlamento —Rumanía, República Checa.

A pesar de que este balance podría considerarse harto positivo, una mirada más de detalle perfila un escenario más complejo. Aunque en la mayoría de los Estados miembros los parlamentos han participado en la toma de decisiones sobre la declaración o la prórroga del estado de excepción correspondiente, en ciertos casos el control no se ha producido de forma reiterada y cada periodos más o menos breves de tiempo - España, Hungría, Luxemburgo- y ello a pesar de que los estados de excepción han estado vigentes en ocasiones durante cinco-seis meses, debilitándose así la función de control ejercida por el Parlamento. Adicionalmente, los parlamentos han tenido escasa o nula capacidad de decisión sobre

113 Ackerman, B., op . cit., pp. 1066-1068. 
las medidas concretas de contención a aplicar en cada momento de la pandemia y ello a pesar de la incidencia de las mismas en los derechos fundamentales de los ciudadanos. En los casos más llamativos, el ejecutivo ha ido muy lejos en su intento de debilitar al parlamento, eludiendo el control parlamentario sobre las prórrogas por la vía de declarar un nuevo estado de excepción — República Checa y Hungría. Harto preocupante parece el caso de Hungría, en el que el estado de riesgo extremo sigue todavía vigente en el momento en que se escriben estas líneas otorgando notables poderes extraordinarios al ejecutivo del país.

Estos elementos llevan a realizar un balance ponderado del uso realizado del Derecho de excepción en los Estados miembros de la UE durante la presente pandemia. La actual crisis sanitaria ha sido sin duda un auténtico test de stress para el Derecho de excepción de todos los Estados analizados, en ocasiones mostrando claras lagunas en su regulación jurídica. Si bien cabe esperar que el legislador aprenda de esos errores, la gestión de la pandemia en algunos Estados miembros permite quizás preguntarse si algún diseño legal, por muy perfeccionado que sea, puede suplir el freno que constituye una democracia plural y una sociedad informada.

TitLE: Use (and abuse?) of states of emergency in the Member States of the European Union during the pandemic

ABSTRACT: The present pandemic has already become a veritable case study to assess the constitutional foundations of states of emergency and their application in practice. As Covid-19 spread to every corner of the planet, countries rushed to adopt harsh containment measures, often within the framework of one of the states of emergency provided for in their constitutional texts. In this context, this paper analyses the use of states of emergency in the Member States of the European Union from March 2020 to June 2021, focusing in particular on the role of national parliaments and domestic courts in preventing possible abuses of power by the executive in the management of the pandemic.

RESUMEN: La presente pandemia se ha convertido ya en un auténtico banco de pruebas para el estudio del Derecho de excepción y su aplicacion práctica. A la par que el Covid-19 se extendía por todos los confínes del planeta, los Estados se apresuraban a adoptar duras medidas de contención, encuadrándolas, en muchas ocasiones, en uno de los estados de excepción previstos por su texto constitucional. En ese contexto, este trabajo analiza la utilización del Derecho de excepción en los Estados miembros de la Unión Europea desde marzo de 2020 basta junio de 2021, centrándose especialmente en el papel de los parlamentos nacionales y los tribunales internos a la hora de evitar eventuales abusos de poder por parte del ejercutivo en la gestión de la pandemia.

KEY WORDS: pandemic, states of emergency, Member States of the European Union.

Palabras Clave: pandemia, estados de excepción, Estados miembros de la Unión Europea.

FECHA DE RECEPCIÓN: 22.07.2021

FECHA DE ACEPTACión: 20.09.2021 
